\title{
NMR Experiments Shed New Light on Glycan Recognition by Human and Murine Norovirus Capsid Proteins
}

\author{
Robert Creutznacher ${ }^{1}$, Thorben Maass ${ }^{1}$, Patrick Ogrissek ${ }^{1}$, Georg Wallmann ${ }^{1}{ }^{1}$, Clara Feldmann ${ }^{1}$, \\ Hannelore Peters ${ }^{1}$, Marit Lingemann ${ }^{2}$, Stefan Taube ${ }^{2, *} * \mathbb{D}$, Thomas Peters ${ }^{1, *}$ and Alvaro Mallagaray ${ }^{1}(\mathbb{D}$ \\ 1 Institute of Chemistry and Metabolomics, University of Lübeck, Ratzeburger Allee 160, \\ 23562 Lübeck, Germany; r.creutznacher@uni-luebeck.de (R.C.); t.maass@uni-luebeck.de (T.M.); \\ patrick.ogrissek@student.uni-luebeck.de (P.O.); gewaelbe@googlemail.com (G.W.); \\ clara.feldmann@student.uni-luebeck.de (C.F.); hanne.pepo@gmail.com (H.P.); \\ alvaro.mallagaraydebenito@uni-luebeck.de (A.M.) \\ 2 Institute of Virology and Cell Biology, University of Lübeck, Ratzeburger Allee 160, \\ 23562 Lübeck, Germany; marit.lingemann@gmail.com \\ * Correspondence: stefan.taube@uni-luebeck.de (S.T.); thomas.peters@uni-luebeck.de (T.P.); \\ Tel.: +49-451-3101-4022 (S.T.); +49-451-3101-3300 (T.P.)
}

Citation: Creutznacher, R.; Maass, T.; Ogrissek, P.; Wallmann, G.;

Feldmann, C.; Peters, H.;

Lingemann, M.; Taube, S.; Peters, T.; Mallagaray, A. NMR Experiments

Shed New Light on Glycan

Recognition by Human and Murine Norovirus Capsid Proteins. Viruses 2021, 13, 416. https://doi.org/ $10.3390 / v 13030416$

Academic Editors: Jacques Le Pendu and Göran Larson

Received: 4 February 2021

Accepted: 3 March 2021

Published: 5 March 2021

Publisher's Note: MDPI stays neutral with regard to jurisdictional claims in published maps and institutional affiliations.

Copyright: (c) 2021 by the authors. Licensee MDPI, Basel, Switzerland. This article is an open access article distributed under the terms and conditions of the Creative Commons Attribution (CC BY) license (https:/ / creativecommons.org/licenses/by/ $4.0 /)$.

\begin{abstract}
Glycan-protein interactions are highly specific yet transient, rendering glycans ideal recognition signals in a variety of biological processes. In human norovirus (HuNoV) infection, histo-blood group antigens (HBGAs) play an essential but poorly understood role. For murine norovirus infection (MNV), sialylated glycolipids or glycoproteins appear to be important. It has also been suggested that $\mathrm{HuNoV}$ capsid proteins bind to sialylated ganglioside head groups. Here, we study the binding of HBGAs and sialoglycans to HuNoV and MNV capsid proteins using NMR experiments. Surprisingly, the experiments show that none of the norovirus P-domains bind to sialoglycans. Notably, MNV P-domains do not bind to any of the glycans studied, and MNV-1 infection of cells deficient in surface sialoglycans shows no significant difference compared to cells expressing respective glycans. These findings redefine glycan recognition by noroviruses, challenging present models of infection.
\end{abstract}

Keywords: norovirus P-domain; chemical shift perturbation; histo blood group antigens; sialoglycans; protein-carbohydrate recognition

\section{Introduction}

Noroviruses are single-stranded (+)-RNA viruses associated with acute gastroenteritis in mammalian hosts. In fact, human noroviruses $(\mathrm{HuNoV})$ are the leading cause for viral gastroenteritis worldwide, with the majority of norovirus outbreaks since 2012 having been caused by genogroup II, genotype 4 (GII.4) viruses [1-3]. Histo-blood group antigens (HBGAs) have been identified as critical structural determinants for HuNoV infection [4-6]. The host enzyme $\alpha-1,2$-fucosyltransferase (FUT2) is essential for HBGA biosynthesis. A functional FUT2 enzyme defines the "secretor" phenotype, where HBGAs are present on the surface of intestinal epithelial cells and become secreted. Individuals lacking FUT2 activity are "non-secretors" and highly resistant against many HuNoV strains. Noroviruses bind HBGA at the interface of a dimeric protruding $(\mathrm{P})$-domain of the viral capsid protein VP1. Despite an increasing number of high-resolution crystal structures that describe the interactions of HBGAs with HuNoV P-domains at atomic resolution, it has remained enigmatic as to how this interaction with HBGAs promotes infection $[7,8]$.

There are exceptions, where HBGA binding could not be determined [9], or mutations notably modulated HBGA binding [10], or expression of FUT2 in permissive cell lines, which is essential for HBGA biosynthesis in continuous cell lines, is not sufficient to initiate infection [11]. Recently, a study in human intestinal enteroids clearly demonstrated the 
necessity of functional FUT2 for HuNoV infection [12]. The same study describes that a GII.3 strain was able to replicate in secretor-negative human intestinal enteroids in the presence of the bile acid glycochenodeoxycholic acid (GCDCA). Therefore, it is likely that additional factors, possibly even a yet unknown proteinaceous entry receptor, as recently identified for murine noroviruses (MNV) [13-16], contribute to HuNoV infections.

In addition to neutral HBGAs, other glycans have been shown to contribute to calicivirus infections. For instance, feline caliciviruses and Tulane virus were shown to require sialic acids for binding and infection $[17,18]$. MNVs share many biological features with $\mathrm{HuNoV}$, such as the intestinal phenotype and fecal oral spread. However, unlike HuNoV they can be easily studied in cell culture and in their native small animal host. It has been shown that the interaction of MNV-1 with murine macrophages was sensitive to neuraminidase treatment and competition with sialic acid specific lectins [19]. Strain specific differences in the ability to bind sialic acid and mutational analysis further suggested a sialic acid binding site [20] in analogy to the HBGA binding sites of GII.4 P-domains of HuNoV. However, structural data for MNV P-domain complexed with glycans are still absent. Bona fide receptors, murine CD300lf or CD300ld, have recently been shown to be essential and sufficient for MNV entry [15,16], and high-resolution crystal structures for the MNV P-domain complexed with CD300lf are available $[13,14]$.

Binding of sialoglycans to HuNoV GII.4 P-domains has been reported using different biophysical techniques [21,22]. Using native mass spectrometry, dissociation constants have been determined for binding of ganglioside-derived glycans to HuNoV GII.4 VA387 P-dimers [22]. Likewise, binding of 3'-sialyllactose to HuNoV GII.4 MI001 P-dimers has been described based on native mass spectrometry, STD NMR, and SPR experiments [21].

A number of studies have addressed the specific interaction between HuNoV GII.4 P-domains (P-dimers) and HBGAs. High-resolution crystal structures have provided a clear picture of P-dimer binding pockets for HBGAs (for a recent review see [23,24]. Consistent with these results, STD NMR experiments have demonstrated that L-fucose is the minimal recognition element required for specific binding [25]. Binding affinities were obtained from STD NMR titrations [21,26-28], and affinities and stoichiometries were provided by mass spectrometry experiments [21,27,29-31], reporting dissociation constants $K_{D}$ in the $\mu \mathrm{M}$ to low $\mathrm{mM}$ range. For the interaction of virus particles with host cells multivalency has to be considered, eventually leading to firm attachment of viruses to plasma membranes. This subject has been studied in detail by using total internal reflection (TIRF) microscopy [32] and quartz microbalance dissipation monitoring [33]. Notably, it has been recognized that different spatial presentation of HBGAs as in type-1 vs. type-2 glycosphingolipids embedded in phospholipid membranes significantly modulates binding avidity [34]. Clearly, presentation of glycans in membranes adds an additional layer of complexity and is relevant for biological function.

Apart from that, it is still important to have access to reliable quantitative glycan binding data. Recent research [35] suggests that existing reports are inconsistent, calling for a systematic reevaluation. Therefore, we set out to collect a comprehensive dataset for binding of glycans to human and murine norovirus capsid proteins based on protein- as well as ligand-based NMR studies.

\section{Materials and Methods}

\subsection{Protein Biosynthesis and Purification}

Recombinant P-domain proteins from GII.4 NoV strains Saga 2006 (GenBank ID: AB447457, aa 225-530), MI001 (KC631814, aa 225-530), and VA387 (AY038600, aa 225-529) were synthesized recombinantly and purified as described previously [35,36]. Due to the purification strategy, the amino acids GPGS were added N-terminally of the native VP1 sequence to yield an enzymatic cleavage site. $\left[U-{ }^{2} \mathrm{H}_{,}^{15} \mathrm{~N}\right]$-labeled protein samples were denatured and refolded to complete the HD back-exchange after expression in deuterated minimal media. Protein species with different deamidation status of N373 were separated using cation exchange chromatography (IEX) with a $6 \mathrm{~mL}$ Resource $\mathrm{S}$ column (GE Health- 
care, Chicago, IL, USA). Samples were applied onto the column in $20 \mathrm{mM}$ sodium acetate buffer ( $\mathrm{pH} 4.9$ ) and eluted with a linear salt gradient up to $500 \mathrm{mM} \mathrm{NaCl}$. Deamidation kinetics of P-domains from strains Saga 2006 and MI001 were obtained by incubation of protein aliquots (1.5 and $0.6 \mathrm{mg} \mathrm{mL}^{-1}$, respectively) in $75 \mathrm{mM}$ sodium phosphate buffer, $100 \mathrm{mM} \mathrm{NaCl}$ (pH 7.3) at $298 \mathrm{~K}$. Samples were subjected to IEX separation at selected time point and peaks in the UV chromatogram at $214 \mathrm{~nm}$ were integrated using Unicorn 7 software (GE Healthcare, Chicago, IL, USA). The decay in N/N dimers was fitted to an exponential decay model and used to derive N373 half-life times. Stability of the N373D Saga 2006 P-domain was assessed by incubation of purified protein aliquots with a concentration of $1.3 \mathrm{mg} \mathrm{mL}^{-1}$ in $75 \mathrm{mM}$ sodium phosphate buffer, $100 \mathrm{mM} \mathrm{NaCl}$ (pH 7.3) for $382 \mathrm{~h}$ at $298 \mathrm{~K}$ and subsequent IEX analysis. Synthesis and purification of MNV P-domains from strains MNV07 (AET79296, aa 228-530, N-terminal addition of GPGS peptide) and CW1 (DQ285629, aa 228-530, N-terminal addition of GP peptide) followed the same strategy as for GII.4 P-domains with the only difference being the running buffer used in the final size exclusion chromatography step (20 mM sodium acetate, $100 \mathrm{mM} \mathrm{NaCl}, \mathrm{pH}$ 5.3). GII.10 Vietnam 026 VLPs (GenBank ID: AF504671) [37] were a gift from Dr. Grant Hansman (University of Heidelberg and the DKFZ, Heidelberg, Germany).

\subsection{Enzymatic Synthesis of Blood Group B-Trisaccharide (3)}

Human Galactosyltransferase B (GTB) was overexpressed from E. coli as previously reported [38] using an optimized purification protocol [39]. Briefly, GTB was eluted from the UDP-affinity column with a $10 \mathrm{mM}$ EDTA solution. Fractions showing UV activity $(280 \mathrm{~nm}$ ) were pooled and dialyzed against $2 \mathrm{~L}$ of $50 \mathrm{mM}$ MOPS pH 6.8, $1 \mathrm{mM}$ DTT, $5 \mathrm{mM}$ $\mathrm{MgCl}_{2}$ and $100 \mathrm{mM} \mathrm{NaCl}$ at room temperature. GTB was stored at $1.2 \mathrm{mg} / \mathrm{mL}$ protein concentration at $4{ }^{\circ} \mathrm{C}$ for no longer than two months. GTB enzymatic activity was measured using radiolabeled uridine-diphospho- $\alpha$-D-[U-14 C]-Galactose lithium salt in $70 \%$ ethanol prior to the synthetic reaction [40], showing specific activity of $10 \mathrm{U} / \mathrm{mg}$. For the enzymatic synthesis of $\mathbf{3}$, the following reactants were mixed in this precise order: H-disaccharide $\mathbf{1}$ (10.5 mg, $30 \mu \mathrm{mol}, 1.00$ equiv.) was dissolved in $15 \mathrm{~mL}$ of $50 \mathrm{mM}$ Bis-Tris buffer $\mathrm{pH} 6.85$ at $37^{\circ} \mathrm{C}$, into which UDP-Galactose $(25.48 \mathrm{mg}, 45 \mu \mathrm{mol}, 1.50$ equiv.), BSA $(0.15 \mathrm{~mL}$ of a stock solution containing $100 \mathrm{mg} / \mathrm{mL}$ BSA in $100 \mathrm{mM}$ Bis-Tris buffer $\mathrm{pH} 6.85$ at $37^{\circ} \mathrm{C}$, final conc.: $1 \mathrm{mg} / \mathrm{mL}), 17 \mathrm{U} / \mathrm{mL}$ CIAP $(10,000 \mathrm{U} / \mathrm{mL})$, GTB $(0.255 \mathrm{~mL}$ of GTB stock solution containing $10 \mathrm{U} / \mathrm{mL}$ and $1.2 \mathrm{mg} / \mathrm{mL} ; 170 \mathrm{mU} / \mathrm{mL}$ final GTB conc. $)$ and $\mathrm{MnCl}_{2}(0.31 \mathrm{~mL}$ of a stock solution containing $1 \mathrm{M} \mathrm{MnCl}_{2}, 20 \mathrm{mM}$ final conc.) ) were added. The $\mathrm{pH}$ of the reaction at the starting point was measured with an electrode $\left(6.85\right.$ at $\left.37^{\circ}\right)$, and the reaction mixture was incubated at $37^{\circ} \mathrm{C}$ under shaking (150 rpm) for 3-7 days. To avoid enzymatic inhibition, the $\mathrm{pH}$ was daily readjusted to $\mathrm{pH}>6.7\left(37^{\circ} \mathrm{C}\right)$ by the addition of a solution containing $500 \mathrm{mM}$ Bis-Tris $\mathrm{pH} 6.85\left(37^{\circ} \mathrm{C}\right)$. After the first $48 \mathrm{~h}$, the reaction was supplemented with extra UDP-Galactose $(8.5 \mathrm{mg}, 15 \mu \mathrm{mol}, 0.50$ equiv.) and GTB (100 mU/mL). Formation of 3 was monitored by TLC (DCM:MeOH 6.5:3.5, Rf = 0.12 in DCM:MeOH 6.5:3.5). When no more $\mathrm{H}$-disaccharide 1 was observed and the $\mathrm{pH}$ remained constant for $24 \mathrm{~h}$, the reaction was quenched by the addition of $20 \mathrm{mM}$ EDTA. Crude was

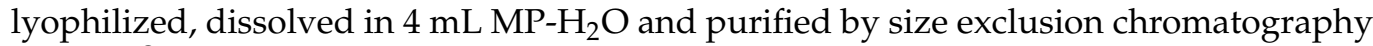
(Bio-Gel ${ }^{\circledR}$ P2, BioRad, Hercules, CA, USA) in $\mathrm{MP}-\mathrm{H}_{2} \mathrm{O}$ (column diameter $2 \mathrm{~cm}$, length $100 \mathrm{~cm}$, retention time $\sim 120 \mathrm{~min}$, flow $0.5 \mathrm{~mL} / \mathrm{min}$ ). Fractions containing 1 were pooled

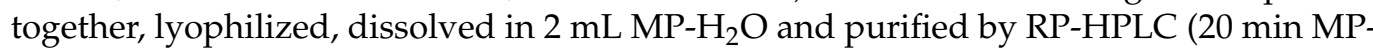
$\mathrm{H}_{2} \mathrm{O}$ with $0.01 \%$ TFA, then gradient to $\mathrm{MP}-\mathrm{H}_{2} \mathrm{O}: \mathrm{MeOH} 4: 1$ with $0.01 \%$ TFA in 60 min, retention time $\sim 21 \mathrm{~min}$, flow $9 \mathrm{~mL} / \mathrm{min}$ ). In both purification steps, the carbohydrate was detected by TLC. After lyophilization, B-trisaccharide 3 (10.01 mg, $19.5 \mu \mathrm{mol}, 65 \%)$ was obtained as a white solid.

M.p. $=204-206 \mathrm{C}^{\circ} \cdot-[\alpha]_{\mathrm{D}}{ }^{21}=+97.69\left(13.09 \mathrm{mg} / \mathrm{mL}, \mathrm{H}_{2} \mathrm{O}\right) .-\mathrm{IR}(\mathrm{KBr}) 3328,2918$, 2115, 1673, $1337 \mathrm{~cm}^{-1}$._ ${ }^{1} \mathrm{H}-\mathrm{NMR}\left(500 \mathrm{MHz}, \mathrm{D}_{2} \mathrm{O}\right) \delta 5.69\left(\mathrm{~d}, J=4.2 \mathrm{~Hz}, 1 \mathrm{H}, \mathrm{H}_{\mathrm{Gal1}}-1\right), 5.20$ $\left(\mathrm{d}, J=3.5 \mathrm{~Hz}, 1 \mathrm{H}, \mathrm{H}_{\mathrm{Gal} 2}-1\right), 5.13$ (d, J = 3.7 Hz, 1H, $\left.\mathrm{H}_{\mathrm{Fuc}}-1\right), 4.33-4.30$ (m, 2H, $\mathrm{H}_{\mathrm{Gal} 2}-5$, $\left.\mathrm{H}_{\mathrm{Gal1}}-4\right)$, 4.18-4.13 (m, 2H, $\left.\mathrm{H}_{\mathrm{Fuc}}-5, \mathrm{H}_{\mathrm{Gal1}}-2\right)$, 4.10-4.06 (m, 2H, H $\left.\mathrm{Gal1}-5, \mathrm{H}_{\mathrm{Gal1}}-3\right)$, 3.96-3.73 
(m, 10H, H $\left.\mathrm{Gal}_{2}-6_{\mathrm{a} \& \mathrm{~b}}, \mathrm{H}_{\mathrm{Gal1}}-6_{\mathrm{a} \& \mathrm{~b}}, \mathrm{H}_{\mathrm{Fuc}}-2, \mathrm{H}_{\mathrm{Fuc}}-4, \mathrm{H}_{\mathrm{Gal} 2}-2, \mathrm{H}_{\mathrm{Fuc}}-3, \mathrm{H}_{\mathrm{Gal} 2}-3, \mathrm{H}_{\mathrm{Gal} 2}-4\right), 1.26$ $\left(\mathrm{d}, J=6.5 \mathrm{~Hz}, 3 \mathrm{H}, \mathrm{CH}_{3 \mathrm{Fuc}}\right) .-{ }^{13} \mathrm{C} \mathrm{NMR}\left(125 \mathrm{MHz}, \mathrm{D}_{2} \mathrm{O}\right) \delta 103.4,96.1,91.2,75.5,75.2$, 74.6, 74.4, 73.8, 72.2, 72.2, 72.2, 71.0, 70.6, 70.5, 67.2, 64.2, 64.1, 18.3.-Anal. calc. for: $\mathrm{C}_{18} \mathrm{H}_{31} \mathrm{~N}_{3} \mathrm{O}_{14}: \mathrm{C}, 42.11 ; \mathrm{H}, 6.09 ; \mathrm{N}, 8.18$. Found: $\mathrm{C}, 43.01 ; \mathrm{H}, 6.08 ; \mathrm{N}, 8.29$.

\subsection{NMR Spectroscopy}

NMR samples were prepared in $3 \mathrm{~mm}$ NMR tubes with a volume of $160 \mu \mathrm{L}$. NMR experiments with $\left[U-{ }^{2} \mathrm{H}_{1}{ }^{15} \mathrm{~N}\right]$-labeled proteins were acquired with samples containing $10 \%$ $\mathrm{D}_{2} \mathrm{O}$. Samples with human NoV P-domains contained $200 \mu \mathrm{M}$ 2,2-dimethyl-2-silapentane5-sulfonate- $\mathrm{d}_{6}$ (DSS- $\mathrm{d}_{6}$, Sigma-Aldrich) and $300 \mu \mathrm{M}$ imidazole (Roth) to monitor the sample $\mathrm{pH}$ [41]. MNV P-domain samples contained $500 \mu \mathrm{M}$ DSS- $\mathrm{d}_{6}$. GII.10 Vietnam026 VLP samples were prepared in PBS buffer $\left(\mathrm{pH}^{*} 7.20\right)$ containing $8 \% \mathrm{D}_{2} \mathrm{O}$ and $100 \mu \mathrm{M}$ DSS- $\mathrm{d}_{6}$. Protein concentrations and sample buffers are compiled in the figure and table legends of the respective datasets or in Table S1. Carbohydrates were obtained from sources given in Table S2. Assignment of resonances from $\alpha$-azido B-trisaccharide 3 and experimental conditions of respective NMR experiments for assignment are given in Tables S3 and S4, respectively.

Unless stated otherwise, NMR spectra were acquired at $298 \mathrm{~K}$ on a Bruker Avance III $500 \mathrm{MHz}$ spectrometer with TCI cryo probe. For acquisition and processing of NMR spectra TopSpin v3.6 (Bruker, Billerica, MA, USA) was used. Protein signal positions and intensities were extracted with CcpNmr Analysis v2.4.2 [42]. ${ }^{1} \mathrm{H}_{1}^{15} \mathrm{~N}$ TROSY HSQC spectra were acquired with $128 \mathrm{~ms}$ acquisition time and a spectral window of $16 \mathrm{ppm}$ in the direct dimension. In the indirect dimension, the spectral window was set to $35 \mathrm{ppm}$ with 430 increments for human NoV P-domains and 256 increments for MNV P-domains. The relaxation delay was $1.5 \mathrm{~s}$. The number of scans was chosen according to the protein concentration of the sample, ranging from 8 to 48 corresponding to measurement times of 1.6 to $6 \mathrm{~h}$. Potential ligand molecules were titrated from highly concentrated, $\mathrm{pH}$-adjusted stock solutions in the same buffer as the NMR sample to minimize dilution effects and pH-artifacts. Titrations of GII.4 NoV P-domains with HBGAs were used to obtain Euclidean Chemical Shift Perturbations (CSPs) $\Delta v$ according to Equation (1).

$$
\Delta v_{\text {eucl }}=\sqrt{\Delta v_{H}^{2}+\Delta v_{N}^{2}}
$$

where $\Delta v_{H}$ and $\Delta v_{N}$ are CSPs in the respective dimensions in units of $\mathrm{Hz}$. The observed $\Delta v_{o b s}$ at a given total ligand concentration $L_{t}$ are linked to the dissociation constant $K_{D}$ via Equation (2) [43].

$$
\Delta v_{o b s}=\Delta v_{\max } \frac{\left(P_{t}+L_{t}+K_{D}\right)-\sqrt{\left(P_{t}+L_{t}+K_{D}\right)^{2}-4 P_{t} L_{t}}}{2 P_{t}}
$$

where $\Delta v_{\max }$ is the maximum CSP at ligand saturation for each signal, and $P_{t}$ is the total monomeric protein concentration. Titration curves for global non-linear least squares fitting were selected according to the magnitude of the CSP at the highest ligand concentration: CSPs larger than the sum of the mean of all CSPs and two standard deviations were used to derive a $K_{D}$ value. Global fitting of significant CSP data was performed using inhouse Python scripts, fit parameter errors were estimated using a bootstrapping approach with 1000 iterations. The titration of $\mathrm{CaCl}_{2}$ to $\mathrm{MNV} \mathrm{CW1} \mathrm{P-domains} \mathrm{with} \mathrm{an} \mathrm{unknown}$ amount of $\mathrm{Ca}^{2+}$ originating from the GCDCA stock solution (Sigma-Aldrich, St. Louis, MO, USA) was analyzed as follows. The initial $\mathrm{Ca}^{2+}$ concentration was estimated based on the minimum of squared residuals when varying $\mathrm{c}\left(\mathrm{Ca}^{2+}\right)$ between 0 and $1 \mathrm{mM}$ before fitting binding isotherms. Finally, for global fitting of Equation (2) to the CSP data this initial $\mathrm{Ca}^{2+}$ concentration was added to the amount of $\mathrm{CaCl}_{2}$ titrated.

STD NMR spectra [44] of ligands binding to P-domains were acquired with relaxation delays of $5 \mathrm{~s}$. Detailed sample conditions are compiled in Table S1 of the supplementary in- 
formation. The number of scans and the resulting experiment time were as follows: 1712 (7 h) for the experiment with the MNV07 strain and 3'SL at 277K, and 3584-4000 (14-16 h) for the remaining STD experiments as described in 3.2 of this manuscript. On-resonance frequencies and saturation pulse strengths were optimized for each individual sample in negative-control experiments without protein and were between -2 and $-4 \mathrm{ppm}$. Offresonance frequencies were set at $200 \mathrm{ppm}$. Saturation times were $2 \mathrm{~s}$ using a cascade of $50 \mathrm{~ms}$ Gaussian pulses with flip angles between $639^{\circ}$ and $674^{\circ}$. STD NMR spectra of compound 13 were measured on a $600 \mathrm{MHz}$ Bruker Avance III HD NMR spectrometer with an Ascend magnet and a TCI cryo probe using a flip angle of $905^{\circ}$. STD NMR experiments with GII.10 Vietnam 026 VLPs were acquired on a $600 \mathrm{MHz}$ Bruker Avance III HD NMR spectrometer with an Ascend magnet and a TXI room temperature probe with the temperature set at $277 \mathrm{~K}$ and a relaxation delay of $20 \mathrm{~s}$. On- and off-resonance frequencies were -4 and $200 \mathrm{ppm}$, respectively. B-trisaccharide was titrated from $1 \mathrm{mM}$ to $50 \mathrm{mM}$ final concentration. The number of scans ranged from 1200 to 200 (13-2 h). A 2 s pulse cascade of $50 \mathrm{~ms}$ Gaussian pulses was used for saturation of protein resonances and a $20 \mathrm{~ms}$ spin-lock filter was used for suppression of protein signals. For the Gaussian pulses the power level was set at $40 \mathrm{~dB}$, corresponding to a flip angle of $675.5^{\circ}$.

STD amplification factors (STD AF) for selected signals were calculated according to Equation (3) with $I_{o f f}$ and $I_{o n}$ being the signal intensities in the respective off- and on-resonance experiments:

$$
S T D A F=\frac{I_{o f f}-I_{o n}}{I_{o f f}} \cdot \frac{L_{t}}{P_{t}}
$$

\subsection{Cell Culture}

Murine microglia cells (BV-2) were maintained in DMEM-10 (Dulbecco's Modified Eagle Medium (Thermo Scientific, Waltham, MA, USA), supplemented with $10 \%$ fetal calve serum (C-C-Pro)) with standard additives (2mM L-glutamine (Biozym, Hessisch Oldendorf, Germany), $100 \mu \mathrm{M}$ non-essential amino acids (Biozym), and 100 units $/ \mathrm{mL}$ penicillin and streptomycin (Biozym)). Pro5 and Lec2 cells were passaged in $\alpha$ MEM5 medium (Modified Eagle Medium $\alpha$ (Thermo Scientific), supplemented with 5\% fetal calve serum (C-C-Pro) and standard additives as above.

\subsection{MNV Cultivation and Titration}

MNV-1 (Isolate CW3, passage 6) was cultivated in BV-2 cells in complete DMEM-10 medium and tissue culture infectious dose (TCID) 50 was determined by end-point dilution in BV-2 cells as described [45].

\subsection{Production of Lentiviral Vectors and Transduction of $\mathrm{CHO}$ Derived Cell Lines}

Recombinant lentiviruses for mCD300LF transduction were produced based on the original protocol [46]. Briefly, the gene of interest expressing construct pWPI msc ${ }^{\text {mCD300LF }}$ was generated, cloning the murine CD300lf cDNA (Genbank NM_001169153.1, GeneScript) with a C-terminal FLAG-tag between SbfI and MluI restriction sites of pWPI msc GUN (generously provided by Thomas Pietschmann, Twincore, Germany). The recombinant lentivirus was generated transfecting $3 \times 10^{6}$ HEK293T cells with $6 \mu \mathrm{g}$ pWPI msc ${ }^{\text {mCD300LF }}$, $3 \mu \mathrm{g}$ of the gag/pol packaging vector pCMV $\Delta$ R8.91 [46], and $1.5 \mu \mathrm{g}$ of the envelope vector pMD.GVSV-G expressing the vesicular stomatitis virus glycoprotein [47], using polyethylenimine (PEI) as a transfection reagent according to the manufacturer's protocol (Polysciences, Inc., Warrington, Philadelphia, PA, USA). At $72 \mathrm{~h}$ post-transfection, viral supernatants were harvested and filtered $(0,45 \mu \mathrm{m}$ pore-size) to remove aggregates. Transduction of Pro5 and Lec 2 cell lines, generously provided by Niklas Arnberg, Umeå University, Sweden, [48] was performed in a 6-well plate incubating confluent Pro5 or Lec 2 cells with $1 \mathrm{~mL}$ of lentivirus supernatant for 6 to $8 \mathrm{~h}$ in the presence of $5 \mu \mathrm{g} / \mathrm{mL}$ polybrene followed by 2 weeks of geneticin (G418) selection. Stable expression of the receptor in Pro5 ${ }^{\mathrm{mCD} 300 \mathrm{LF}}$ and Lec $2^{\mathrm{mCD} 300 \mathrm{LF}}$ cell lines was verified susceptibility to MNV-1 
infection. MNV-1 titers yielded up to $2 \times 10^{8} \mathrm{TCID}_{50}$ per $\mathrm{ml}$, which is comparable to naturally susceptible cell lines.

\section{Results}

A number of glycans were selected as ligands to probe binding to human and murine norovirus capsid proteins. The glycans in Scheme 1 represent key structural motifs of HBGAs, and sialoglycans. We also included the Galili epitope [49,50] 11, not present in humans, as well as the Forssman antigen [51] $\mathbf{1 3}$ as negative controls that should bind neither to human nor to murine noroviruses [50]. Protein-based chemical shift perturbation (CSP) NMR binding experiments are known to provide unambiguous and highly accurate binding affinities for ligand molecules such as glycans binding to proteins under near-physiological conditions [43]. However, the need to label the proteins with stable isotopes often discourages the use of this method, when proteins are larger than 20 to $30 \mathrm{kDa}$. Proteins of the size of the P-dimers studied here, with molecular weights around $70 \mathrm{kDa}$, are considered a challenge. Fortunately, we succeeded in providing high-yield expression protocols for stable isotope labeled HuNoV P-domains before [35,36,52], and recently we established such a protocol also for MNV P-domains (see accompanying paper). For the present study we employed recombinantly expressed and uniformly ${ }^{2} \mathrm{H}_{1}^{15} \mathrm{~N}$-labeled P-domains of selected VP1 capsid proteins. All analyzed P-domains formed dimers (P-dimers) and all $\mathrm{HuNoV}$ P-dimers showed the previously reported HBGA binding specificities. To systematically study binding of HBGAs and sialoglycans, we chose P-dimers of previously studied human GII.4 strains, Saga and MI001. For the GII.4 strain VA387, which has been reported to bind sialoglycans [22], only binding of sialoglycans was cross-examined. To study potential MNV-glycan interactions, we selected the MNV-1 CW1 strain, for which infectiousness has previously been shown to depend on sialic acid [19], and an MNV strain isolated in 2007 (MNV07). CSP NMR experiments were complemented by saturation transfer difference (STD) NMR [44] experiments using unlabeled recombinant P-dimers and human GII.10 Vietnam 026 virus-like particles (VLPs).

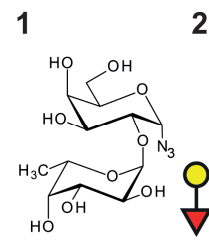

6

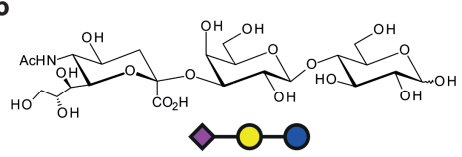

8

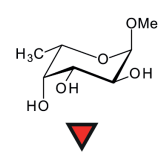

13

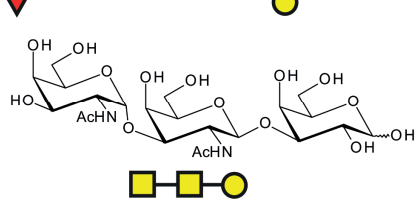

3

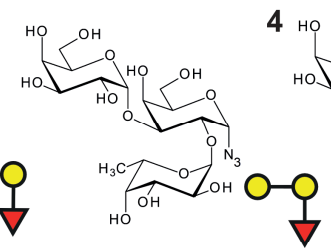

7

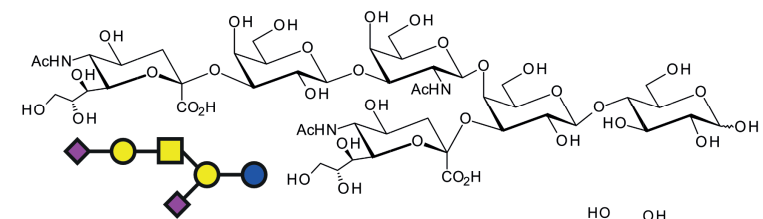

$9 \mathrm{OH} \mathrm{OH} \quad 10$

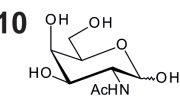

11
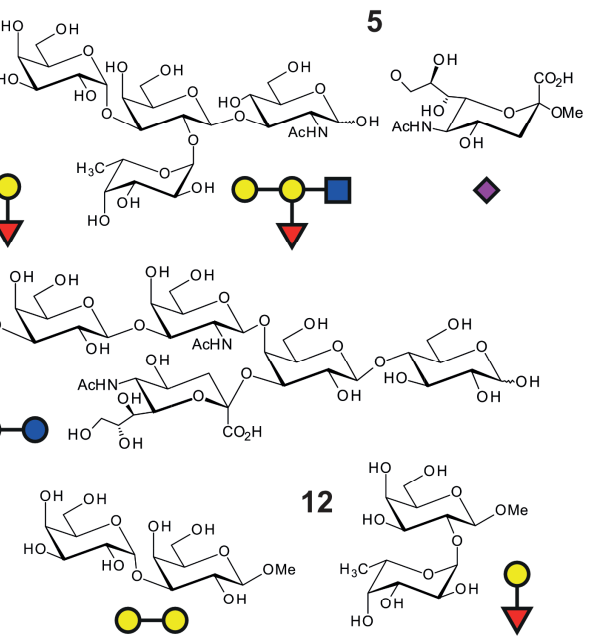

12

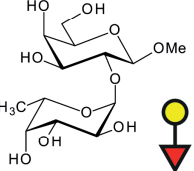

14

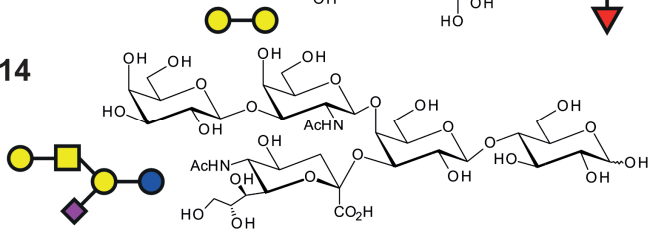

Scheme 1. Oligosaccharides used in this study. 1 and 12: blood group H-disaccharide; 2: blood group A trisaccharide; 3 : blood group B trisaccharide (azido group at the anomeric position); 4: blood group B tetrasaccharide (reducing form); 5 : methyl glycoside of $N$-acetyl $\alpha$-D-neuraminic acid (sialic acid); 6: 3'-sialyllactose (3'SL, glycan part of GM3 ganglioside); 7: glycan part of GD1a ganglioside; 8: methyl $\alpha$-L-fucopyranoside; 9: D-galactose; 10: $N$-acetyl D-galactosamine; 11: Galili epitope; 13: Forssman antigen; 14: glycan part of GM1a ganglioside. 


\subsection{Chemical Shift Perturbation (CSP) NMR Experiments Provide Accurate Dissociation Constants for HBGAs Binding to Human GII.4 SAGA and MI001 P-Dimers}

We employed TROSY HSQC based CSP NMR experiments to study binding of HBGAs to uniformly ${ }^{2} \mathrm{H}_{1}{ }^{15} \mathrm{~N}$-labeled P-dimers. For GII.4 Saga P-dimers an almost complete backbone assignment is available [35]. As the HuNoV P-dimers studied here share more than $90 \%$ sequence identity one may expect assignments to be transferrable from TROSY HSQC spectra of Saga P-dimers. In fact, the overall cross-peak patterns are rather similar. However, assignment transfer is straightforward only in less crowded spectral regions (cf. Figure S1). For the measurement of binding affinities of HBGAs an assignment is not necessary.

From our previous study, we learned that highly specific spontaneous deamidation of the asparagine residue N373 of Saga P-dimers leads to the formation of an iso-aspartate residue in that position (iD373), essentially switching off HBGA binding [35]. Therefore, prior to CSP titrations we checked the deamidation rate of MI001 P-dimers using ionexchange chromatography, showing that the half-lives at room temperature are essentially identical to the ones of Saga P-dimers [35] (cf. Figure S2). This is important because the duration of CSP titration experiments is in the range of several hours, and the amount of deamidated protein has to be kept at a minimum during that time period. Therefore, to analyze binding of HBGAs to non-deamidated GII.4 Saga and MI001 P-dimers (N/N P-dimers; both monomers carry $\mathrm{N}$ in position 373 ), freshly prepared protein samples were purified by ion-exchange chromatography and immediately subjected to CSP titration experiments (Figure 1). Monitoring CSPs for purified fully deamidated samples of Saga P-dimers (iD/iD P-dimers; both monomers carry iD in position 373) was not time-critical since these samples were stable and did not change over time. Dissociation constants in the low $\mathrm{mM}$ range were determined for binding of blood group $\mathrm{H}$-disaccharide, A-trisaccharide, B-trisaccharide, and B-tetrasaccharide to N/N Saga P-dimers, and to N/N MI001 P-dimers. For iD/iD P-dimers dissociation constants could only be estimated since binding was extremely weak, in the high mM range. All data are compiled in Table 1, and representative CSP titration curves are shown in Figure 1c,d.

Table 1. Dissociation constants $K_{D}$ for binding of HBGAs to NoV P-domains and VLPs. Rows 1 to 7 : $\mathrm{K}_{\mathrm{D}}$ values from CSP NMR titrations of P-dimers (cf. Figure 1 for corresponding titration curves; the titration curve for A-Tri 2 is found in the supporting information. Figure S6). NMR samples were prepared in $75 \mathrm{mM}$ sodium phosphate, $100 \mathrm{mM} \mathrm{NaCl}$ (pH 7.3). Protein concentrations were 230-300 $\mu \mathrm{M}$ for Saga N/N P-domains, $210 \mu \mathrm{M}$ for Saga iD/iD P-domains, $240 \mu \mathrm{M}$ for Saga N373D, and $220 \mu \mathrm{M}$ for MI001. Rows 8 and 9: $\mathrm{K}_{\mathrm{D}}$ values from STD NMR experiments acquired at $277 \mathrm{~K}$ for VLPs.

\begin{tabular}{ccc}
\hline NoV Strain & Ligand & $\mathbf{K}_{\mathbf{D}} / \mathbf{m} \mathbf{M}$ \\
\hline GII.4 Saga (N/N) & H-Dis 1 & $30.0 \pm 1$ \\
GII.4 Saga (N/N) & A-Tri 2 & $4.3 \pm 0.4$ \\
GII.4 Saga (N/N) & B-Tri 3 & $6.7 \pm 0.4$ \\
GII.4 Saga (N/N) & B-Tetra 4 & $12.0 \pm 1$ \\
GII.4 Saga (iD/iD) & B-Tri 3 & ca. 60 \\
GII.4 Saga (N373D) & B-Tri 3 & $2.4 \pm 0.1$ \\
GII.4 MI001 (N/N) & B-Tri 3 & $4.3 \pm 0.4$ \\
GII.10 Vietnam 026 VLPs & B-Tri 3 & $7.9 \pm 0.7$ \\
GII.10 Vietnam 026 VLPs (with saturating amounts of GCDCA [a]) & B-Tri 3 & $9.0 \pm 1$ \\
\hline [a] Glycochenodeoxycholic acid. & &
\end{tabular}

We prepared the N373D mutant of the GII.4 Saga P-domain, with the advantage that no spontaneous deamidation is possible in this position. At room temperature N373D P-dimers are stable for at least several weeks as shown by ion exchange chromatography (Figure S3), and as qualitatively supported by monitoring ${ }^{1} \mathrm{H},{ }^{15} \mathrm{~N}$ TROSY HSQC spectra of uniformly ${ }^{2} \mathrm{H},{ }^{15} \mathrm{~N}$-labeled P-dimers over time. The dissociation constant for 
B-Tri 3 (Figure $1 \mathrm{~d}$ and Table 1 ) is slightly smaller than in the case of N/N Saga P-dimers (2.4 vs. $6.7 \mathrm{mM}$, respectively).

a

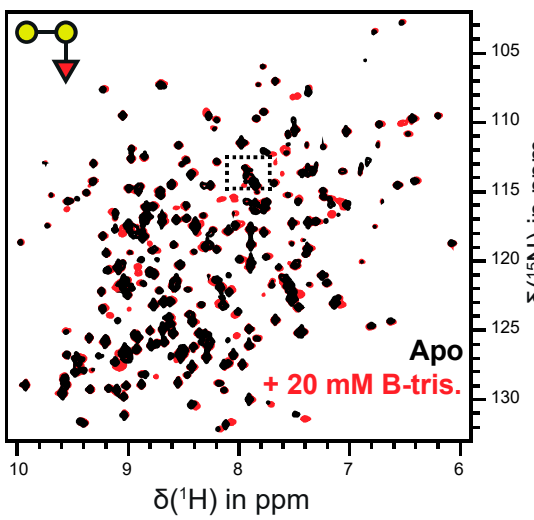

C

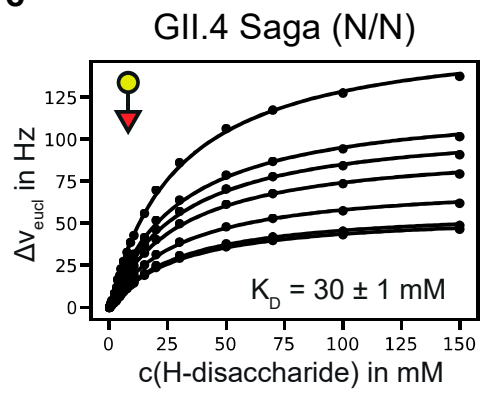

d

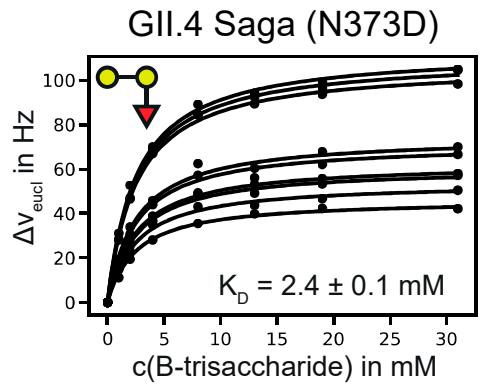

b

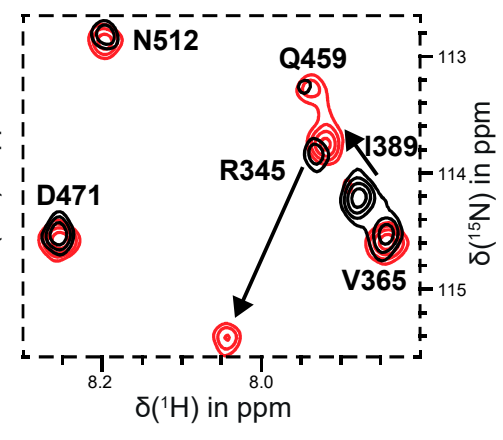

Gll.4 Saga (N/N)

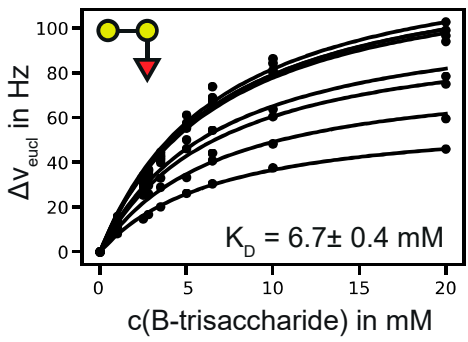

GII.4 MI001 (N/N)

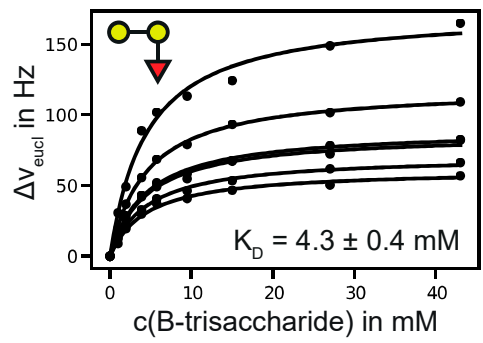

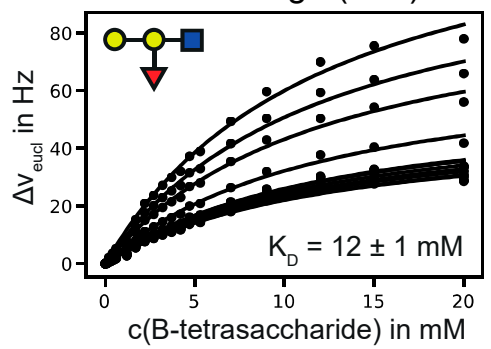

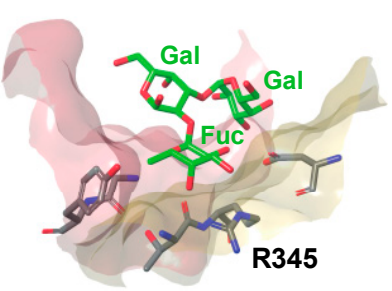

GIl.4 Saga (N/N)

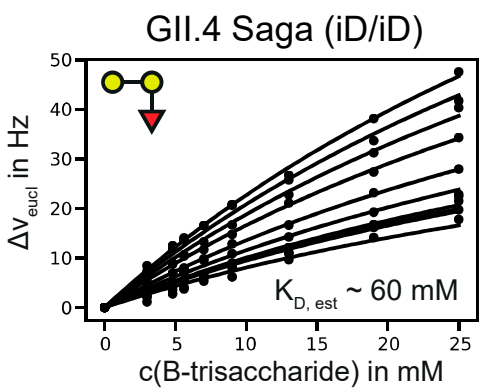

Figure 1. (a) ${ }^{1} \mathrm{H}^{15} \mathrm{~N}$ TROSY HSQC spectra of $\left[U_{-}{ }^{2} \mathrm{H},{ }^{15} \mathrm{~N}\right]$-labeled GII.4 Saga P-dimers in the absence and presence of B-trisaccharide 3. The insert is highlighting CSPs due to binding of 3. (b) HBGA binding pocket of GII.4 Saga P-dimers (pdb $4 \times 06$ ) highlighting the close proximity between the L-fucose residue and R345 causing the strong CSP shown in (a). (c) CSP titration curves for H-disaccharide 1, B-trisaccharide 3, and B-tetrasaccharide 4 (from left to right). (d) CSP titration curves for B-trisaccharide 3 binding to the N373D mutant of GII.4 Saga P-dimers, to MI001 P-dimers, and to fully deamidated GII.4 Saga P-dimers (from left to right).

In previous studies we had observed discontinuities in STD NMR titration curves, which we erroneously assigned to cooperative HBGA binding [21,26,27]. In the light of our more recent studies [35] and the data collected here it is clear that there is no cooperativity associated with HBGA binding to P-dimers or VLPs. The reason for the observed discontinuities must be due to other causes. Therefore, we reevaluated our old STD NMR titration datasets $[26,27]$ by simply ignoring the discontinuities in the binding isotherms and applying a simple one-site binding model instead (cf. Figure S4). The dissociation constants obtained from this analysis are shown in Table S5 The dissociation constants for a $\mathrm{H}$-disaccharide and for a B-trisaccharide derivative (entries 7 and 8 in Table S5) match the results for H-Dis $\mathbf{1}$ and B-Tri 3 from CSP NMR titrations (Table 1) quite well. In the course of these reevaluations we also performed an additional experiment to elucidate potential crosstalk [53] between binding of glycochenodeoxycholic acid (GCDCA) 
and binding of B-Tri 3 to GII.10 Vietnam 026 VLPs. We obtained corresponding STD NMR titration curves in the absence and in the presence of saturating amounts of GCDCA [36], showing that GCDCA has no influence on the dissociation constant $K_{D}$ of B-Tri 3 (Figure 2 and Table 1).

a
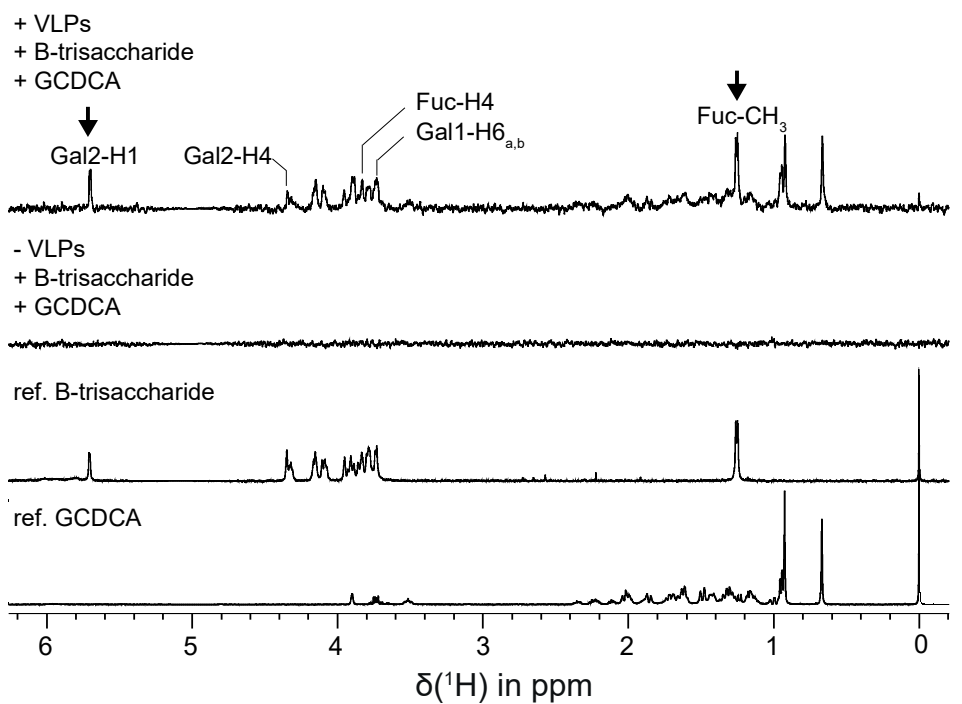

b

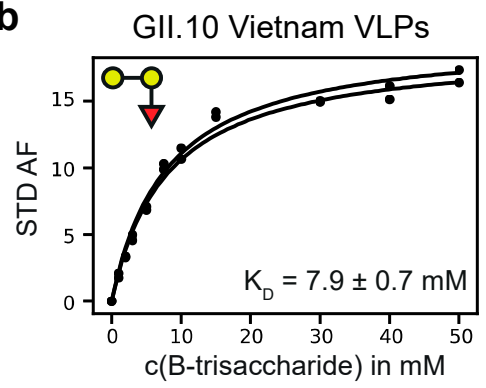

GII.10 Vietnam VLPs

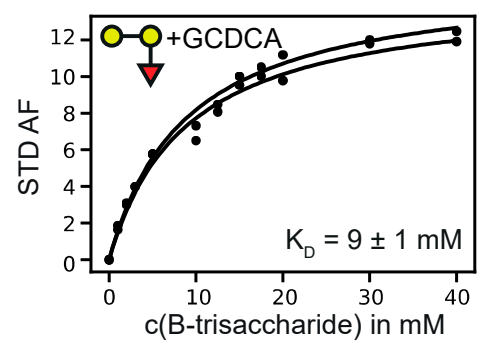

Figure 2. (a) STD NMR experiments for a sample of GII.10 Vietnam 026 VLPs $(0.87 \mathrm{mg} / \mathrm{mL})$ and 2 mM B-trisaccharide 3 in the absence and presence of saturating amounts of GCDCA (1 mM). For water suppression an excitation sculpting sequence [54] was used. The signals of the anomeric protons of $\beta$-D-galactose (Gal1) and $\alpha$-L-fucose (Fuc) are hidden by the water signal (suppressed). The arrows denote the signals of the anomeric proton of the $\alpha$-D-galactose residue (Gal2) and of the C6-methyl group of the $\alpha$-L-fucose residue (Fuc) of 3. The STD intensities of these signals were used for the determination of dissociation constants from STD NMR titration experiments. (b) Binding isotherms for H1 of Gal2 and the C6-methyl group of Fuc of 3 in the absence (left) and in the presence of GCDCA (right). Samples contained $0.95 \mathrm{mg} / \mathrm{mL} \mathrm{or} 0.87 \mathrm{mg} / \mathrm{mL}$ GII.4 Vietnam 026 VLPs according to the absence or presence of GCDCA, respectively. All samples were prepared in PBS buffer $\left(8 \% \mathrm{D}_{2} \mathrm{O}\right)$ at a $\mathrm{pH}^{*}$ of 7.20. NMR experiments were acquired at $600 \mathrm{MHz}$ at a temperature of $277 \mathrm{~K}$.

\subsection{MNV P-Domains Do Not Bind to HBGAs or Other Neutral Glycans}

To address the question whether MNV P-dimers bind to glycans we subjected a variety of glycan ligands (Table 2) to protein-based as well as ligand-based NMR binding experiments, i.e., CSP and STD NMR experiments, respectively. For CSP experiments, we prepared samples of $\left[\mathrm{U}^{-2} \mathrm{H}_{1}{ }^{15} \mathrm{~N}\right]$-labeled samples of MNV P-domains of the strains CW1 and MNV07 as described in detail in an accompanying paper, addressing stabilization and reorientation of MNV P-dimers in the presence of a specific bile acid, GCDCA.

Briefly, without GCDCA, MNV P-domains exist in an equilibrium of monomeric and dimeric species. At higher concentrations above ca. $100 \mu \mathrm{M}$, dimers prevail. Addition of GCDCA shifts that equilibrium completely towards the dimeric form and at the same time causes conformational rearrangements within the P-dimers (details are found in the accompanying paper). For the purpose of the present study, it is sufficient to note that binding of glycans was tested in the absence and in the presence of GCDCA. We applied a variety of conditions (Table 2) to probe for interactions of MNV P-dimers with HBGAs or other neutral glycans, but we could neither detect CSPs nor STD effects, demonstrating that MNV P-dimers do not recognize HBGAs or other neutral glycans listed in Table 2 (corresponding overlays of ${ }^{1} \mathrm{H}_{1}^{15} \mathrm{~N}$ TROSY HSQC spectra of P-dimers in the absence and presence of glycans as well as STD NMR spectra are compiled in the supplementary information clearly illustrating the negative results). 
Table 2. Glycans tested negative for binding to MNV P-domain with and without GCDCA. NMR samples were prepared in the following buffers. A: $75 \mathrm{mM}$ sodium phosphate, $100 \mathrm{mM} \mathrm{NaCl}$ (pH 6), A*: A with $20 \mathrm{mM}$ sodium phosphate, B: $20 \mathrm{mM}$ sodium acetate, $100 \mathrm{mM} \mathrm{NaCl}$ ( $\mathrm{pH}$ 5.3), B*: B with sodium acetate-d3 in D2O. Additional experimental conditions such as temperatures and protein and ligand concentrations are given in Table S1.

\begin{tabular}{|c|c|c|c|c|c|c|}
\hline MNV Strain & Glycan Ligand & $\operatorname{Exp}[a]$ & $B[b]$ & GCDCA & EDTA & $\mathrm{Ca}^{2+}$ \\
\hline CW1 & Fuc 8 & STD & $\mathrm{B}$ & - & - & - \\
\hline CW1 & H-Dis 12 & CSP & $\mathrm{B}$ & + & - & - \\
\hline CW1 & A-Tri 2 & STD & $\mathrm{B}^{*}$ & + & - & - \\
\hline MNV07 & B-Tri 3 & CSP & $\mathrm{B}$ & - & - & - \\
\hline CW1 & B-Tri 3 & CSP & $\mathrm{B}$ & - & - & - \\
\hline MNV07 & B-Tri 3 & STD & B & + & - & - \\
\hline CW1 & B-Tri 3 & CSP & B & + & - & - \\
\hline CW1 & B-Tri 3 & CSP & $\mathrm{B}$ & + & + & - \\
\hline CW1 & GalNAc 10 & STD & $\mathrm{B}^{*}$ & + & - & - \\
\hline CW1 & Fuc 8, Gal 9 & CSP & B & + & - & - \\
\hline CW1 & Galili Dis $\mathbf{1 1}$ & CSP & $\mathrm{B}$ & + & - & - \\
\hline CW1 & Forssman antigen 13 & STD & $\mathrm{B}^{*}$ & + & - & - \\
\hline MNV07 & Neu5Ac 5 & STD & $A^{*}$ & - & - & - \\
\hline CW1 & Neu5Ac 5 & CSP & $\mathrm{B}$ & + & - & - \\
\hline CW1 & Neu5Ac 5 & CSP & B & + & + & - \\
\hline CW1 & Neu5Ac 5 & CSP & A & + & - & + \\
\hline CW1 & 3'SL 6 & CSP & B & - & - & - \\
\hline MNV07 & $3^{\prime}$ SL 6 & STD & B & + & - & - \\
\hline CW1 & $3^{\prime}$ SL 6 & CSP & B & + & - & - \\
\hline CW1 & 3'SL 6 & CSP & B & + & - & + \\
\hline CW1 & 3'SL 6 & CSP & B & + & + & + \\
\hline CW1 & GM1a 14 & CSP & $\mathrm{B}$ & + & - & - \\
\hline MNV07 & GD1a 7 & CSP & $A^{*}$ & & - & - \\
\hline
\end{tabular}

[a] Type of NMR experiment performed for detection of binding. [b] Buffer used, cf. legend.

In the course of these glycan-binding studies, we noticed that MNV P-domains, saturated with GCDCA, specifically bind $\mathrm{Ca}^{2+}$ with affinities in the $\mu \mathrm{M}$ range. We also detected binding of $\mathrm{Mg}^{2+}$ and $\mathrm{Mn}^{2+}$ ions. Bivalent metal ion binding is illustrated in Figure 3. If a ligand sample contains metal ion impurities CSPs can obstruct or fake ligand binding. Therefore, it is important to either quantitatively remove bivalent metal ions prior to chemical shift titration experiments with glycan ligands or to saturate metal ion binding pockets. Otherwise, wrong positive results may be obtained. As an example, traces of $\mathrm{Mn}^{2+}$ resulting from chemoenzymatic synthesis of B-Tri 3 using human blood group B galactosyltransferase cause cross peaks in ${ }^{1} \mathrm{H}_{1}{ }^{15} \mathrm{~N}$ HSQC TROSY spectra to disappear. After addition of EDTA the peaks recur, clearly demonstrating that the effect is not due to the presence of B-Tri 3. (cf. Figure S5).

\subsection{MNV and GII.4 P-Dimers Do Not Recognize Sialic Acid}

Earlier studies with MNV showed that attachment to murine macrophages involves sialic acid bearing glycolipids or glycoproteins. Based on mutagenesis experiments a glycan (sialic acid) binding site has been proposed, located in the P-domain in a region corresponding to the HBGA binding site of human GII.4 noroviruses $[19,20]$. To test this hypothesis, we subjected $\left[U-{ }^{2} \mathrm{H},{ }^{15} \mathrm{~N}\right]$-labeled and unlabeled MNV P-dimers of the strains CW1 and MNV07 to CSP and STD NMR experiments, respectively, using sialic acid and sialic acid bearing glycans as ligands (Table 2). As GCDCA plays an important role in stabilizing MNV P-dimers, CSP NMR experiments were performed in the absence and in the presence of GCDCA. We also varied the $\mathrm{pH}$ and used varying buffer compositions to make sure that the observations do not depend on these conditions. In fact, binding of sialic acid glycans was not observed under any of the settings chosen. To illustrate these negative findings, Figure 4 shows a representative STD NMR spectrum of a sample consisting of MNV07 P-dimers in the presence of saturating amounts of GCDCA and 
$2 \mathrm{mM} 3^{\prime}$-sialyllactose ( $\left.3^{\prime} \mathrm{SL}\right)$ as found in GM3 gangliosides. It is obvious that the only STD signals result from GCDCA. In Figure S8, we compile more STD NMR spectra and TROSY HSQC spectra in the absence and presence of sialoglycans to further illustrate these negative results.

a

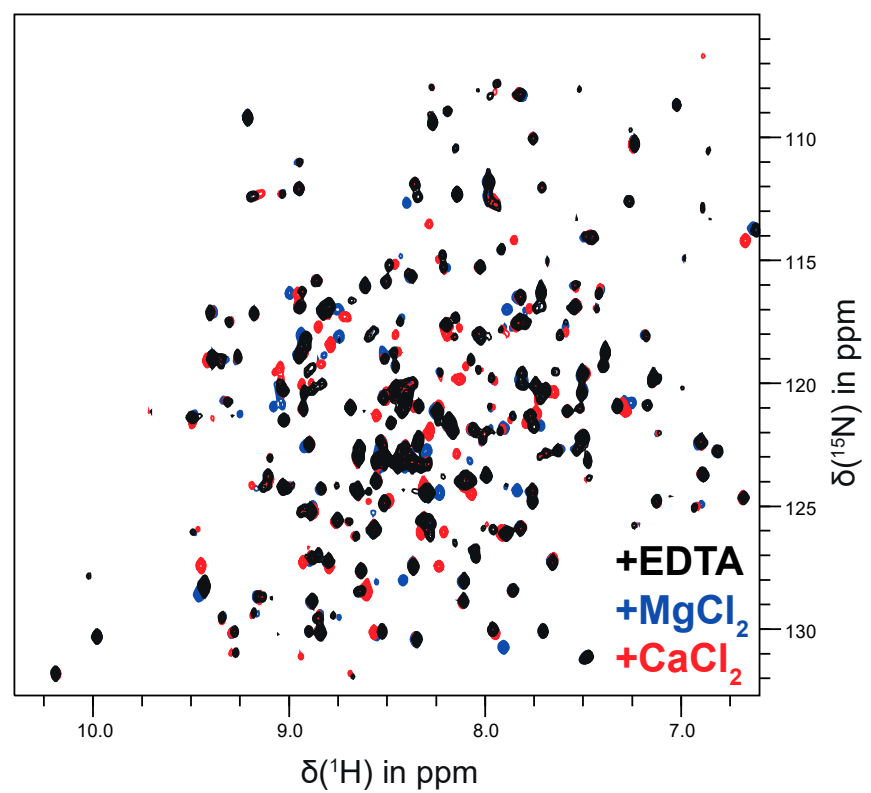

b
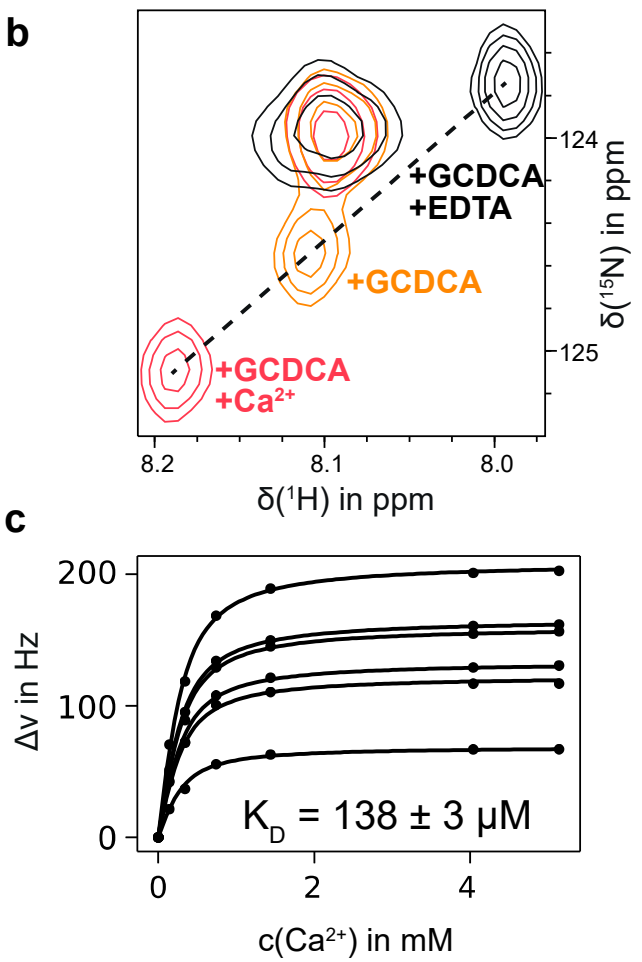

Figure 3. (a) ${ }^{1} \mathrm{H}^{15} \mathrm{~N}$ TROSY HSQC spectra of $150 \mu \mathrm{M}\left[U_{-}{ }^{2} \mathrm{H},{ }^{15} \mathrm{~N}\right]$-labeled CW1 P-domain saturated with GCDCA (black contours) and in the presence of $5 \mathrm{mM} \mathrm{MgCl}_{2}$ (blue contours) or $\mathrm{CaCl}_{2}$ (red contours). No assignment is available yet, but the same set of signals is affected by both $\mathrm{Mg}^{2+}$ and $\mathrm{Ca}^{2+}$ indicating a shared binding pocket. (b) Effects of adding EDTA or $\mathrm{Ca}^{2+}$ to the P-domain in the presence of saturating amounts of GCDCA. Black contours correspond to the respective spectrum in (a). Addition of EDTA (black) shifts the resonance signal in the opposite direction as addition of $\mathrm{Ca}^{2+}$ (red) showing that GCDCA contains a significant amount of calcium ions. Therefore, all P-domain samples having GCDCA added also contain an undefined amount of $\mathrm{Ca}^{2+}$. (c) Euclidean CSPs can be calculated from a $\mathrm{Ca}^{2+}$ titration series with the chemical shifts of an EDTA-treated sample taken as starting points. Due to the $\mathrm{Ca}^{2+}$ contamination the total Ca ${ }^{2+}$ concentration during the titration is not known precisely. Using the amount of added $\mathrm{Ca}^{2+}$ ions, a global least-squares minimization of CSPs larger than two standard deviations were used to derive both, the initial $\mathrm{Ca}^{2+}$ concentration and the dissociation constant $\mathrm{K}_{\mathrm{D}}$. This approach yields a $\mathrm{K}_{\mathrm{D}}$ value of $138 \mu \mathrm{M}$. With $300 \mu \mathrm{M}$ GCDCA, the initial Ca ${ }^{2+}$ contamination was determined as $140 \mu \mathrm{M}$. Spectra were acquired in $20 \mathrm{mM}$ sodium acetate, $100 \mathrm{mM} \mathrm{NaCl}(\mathrm{pH} 5.3)$. $\mathrm{Ca}^{2+}$ was titrated to a sample containing $250 \mu \mathrm{M}$ P-domain.

Recent studies reported binding of sialic acid-bearing glycans to HuNoV P-dimers of the GII.4 strains VA387 [22] and MI001 [21]. Therefore, we used $\left[U-{ }^{2} \mathrm{H}_{1}{ }^{15} \mathrm{~N}\right]$-labeled P-dimers of VA387, MI001, and Saga to probe binding of sialoglycans using CSP NMR experiments (Table 3, Figure $4 \mathrm{~b}$ and Figure S7). To our surprise we did not observe effects of binding under any of the conditions chosen, strongly suggesting that previous positive results were due to experimental artifacts. A study using native MS confirms this conclusion and addresses the underlying experimental problems in full detail (Charlotte Uetrecht, personal communication, manuscript in preparation). In this context, it is interesting to note that published MS based data were not fully consistent. Prior to the report on binding of sialic-acid bearing glycans [22] an earlier study from the same laboratory had stated that neither 3 '-sialyllactose nor 6'-sialyllactose bind to VA387 P-dimers [31]. 


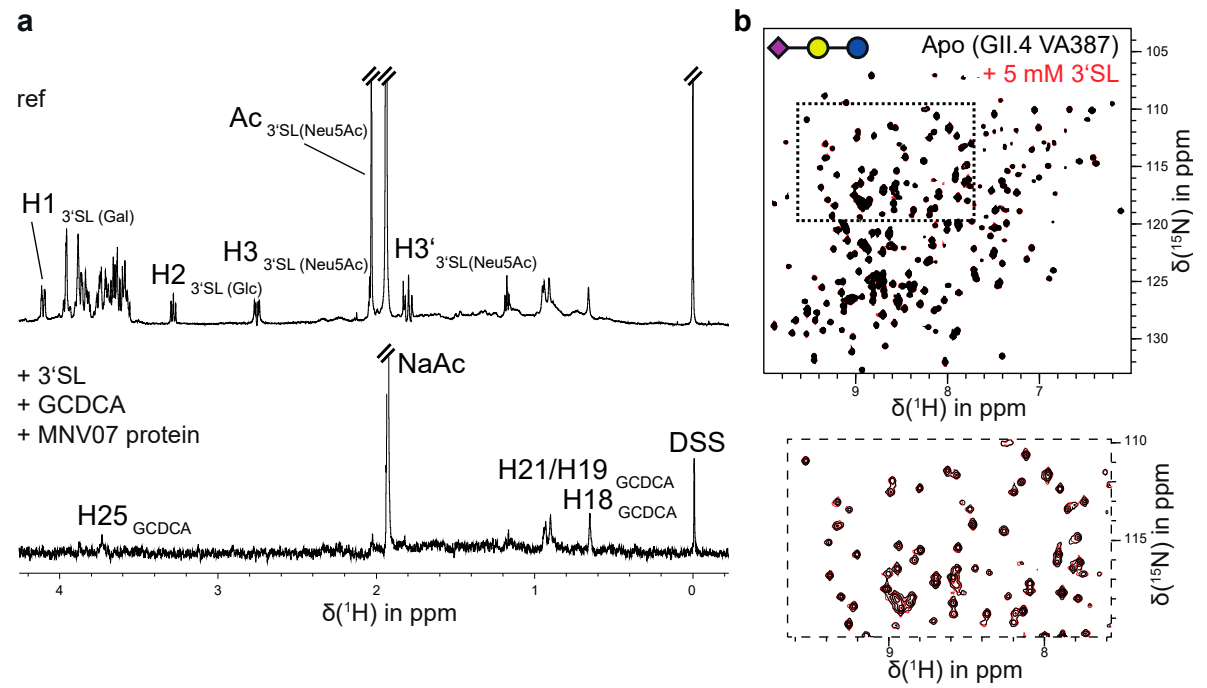

Figure 4. MNV and GII.4 P-domains do not bind to sialic acid containing glycans. (a) STD NMR spectra of MNV07 P-domains in the presence of the ligand GCDCA and $3^{\prime}$-sialyllactose (3'SL). There is no saturation transfer to protons of $3^{\prime}$ SL. Only GCDCA signals show STD effects. The sample contained $80 \mu \mathrm{M}$ protein in $20 \mathrm{mM}$ sodium acetate buffer ( $\mathrm{pH}$ 5.3), $250 \mu \mathrm{M}$ GCDCA, and $2 \mathrm{mM}$ $3^{\prime} \mathrm{SL}$. Spectra were acquired at $298 \mathrm{~K}$ at $600 \mathrm{MHz}$. (b) ${ }^{1} \mathrm{H},{ }^{15} \mathrm{~N}$ TROSY HSQC spectra of $170 \mu \mathrm{M}$ $\left[U-{ }^{2} \mathrm{H},{ }^{15} \mathrm{~N}\right]$-labeled HuNoV GII.4 VA387 P-dimers with and without $3^{\prime}$ SL showing no binding of $3^{\prime} \mathrm{SL}$. A representative section of the spectra highlights the absence of CSPs upon 3'SL addition. The sample was prepared in $75 \mathrm{mM}$ sodium phosphate buffer, $100 \mathrm{mM} \mathrm{NaCl}$ (pH 7.3).

Table 3. Sialylated ganglioside glycans tested negative for binding to human NoV P-domains. NMR samples were prepared in the following buffers. A: $20 \mathrm{mM}$ sodium phosphate ( $\mathrm{pH} 7.4), \mathrm{B}: 75 \mathrm{mM}$ sodium phosphate, $100 \mathrm{mM} \mathrm{NaCl}$ (pH 7.3), C: $100 \mathrm{mM}$ sodium acetate (pH 4.6), D: $200 \mathrm{mM}$ ammonium acetate (pH 7.3), E: $50 \mathrm{mM}$ sodium phosphate, $20 \mathrm{mM} \mathrm{NaCl}$ (pH 7.4), F: B + $5 \mathrm{mM}$ GCDCA, G: $20 \mathrm{mM}$ sodium acetate, $100 \mathrm{mM} \mathrm{NaCl}$ (pH 5.3). Protein concentrations were $110-860 \mu \mathrm{M}$ for Saga N/N P-domains, $100 \mu \mathrm{M}$ for Saga iD/iD P-domains, 80-180 $\mu \mathrm{M}$ for MI001, and $170 \mu \mathrm{M}$ for VA387. Carbohydrate concentrations were 5-16 mM. NMR spectra were acquired at $298 \mathrm{~K}$.

\begin{tabular}{ccc}
\hline HuNoV Strain & Glycan Ligand & Buffer \\
\hline GII.4 Saga (N/N) & Neu5Ac 5 & A \\
& 3'SL 6 & B \\
& 3'SL 6 & C \\
GII.4 Saga (iD/iD) & 3'SL 6 & D \\
GII.4 MI001 (N/N) & 3'SL 6 & B \\
& Neu5Ac 5 & B \\
GII.4 VA387 (N/N) & 3'SL 6 & E \\
& 3'SL 6 & B \\
& 3'SL 6 & F \\
\hline
\end{tabular}

3.4. Sialic Acid on CHO Derived Cells Expressing the MNV-1 Entry Receptor Does Not Contribute to Infection

In order to determine the effect of MNV-1 infection, susceptible cell lines lacking sialic acid on their cell surface were infected with MNV-1 (Figure 5). For this, a parental CHO derived cell line (Pro5) and a recombinant Pro5 mutant (Lec2), deficient in transporting CMP-sialic acid into the Golgi compartment [48], were transduced to stably express the MNV-1 entry receptor mCD300LF. The parental Pro5 ${ }^{\mathrm{mCD} 300 \mathrm{LF}}$ and recombinant Lec2 mCD300LF cells support MNV infection similarly to naturally susceptible murine monocyte derived cell lines. The absence of sialic acid from the cell surface of Lec2 ${ }^{\mathrm{mCD} 300 \mathrm{LF}}$ cells as described previously [48] was monitored by FITC-conjugated wheat-germ agglutinin 
staining. Binding was determined inoculating Pro ${ }^{\mathrm{mCD}}$ and $\mathrm{Lec} 2^{\mathrm{mCD}}$ with $\mathrm{MNV}-1$ with an MOI of 5 for $1 \mathrm{~h}$ on ice removing the inoculum and determining the TCID ${ }_{50}$ of virions bound the cells. Infection was determined by inoculating respective cells with MNV-1 with an MOI of 0.05 for $1 \mathrm{~h}$ on ice removing the inoculum and determining infection between 0 and $72 \mathrm{~h}$ post infection by end-point dilution. No significant differences were observed at any analyzed timepoint, suggesting that cell surface sialic acids do not contribute to MNV-1 infection in this system.

a

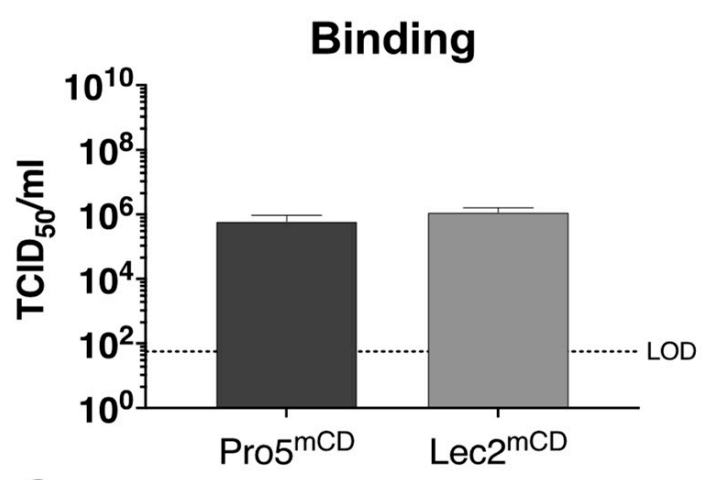

C

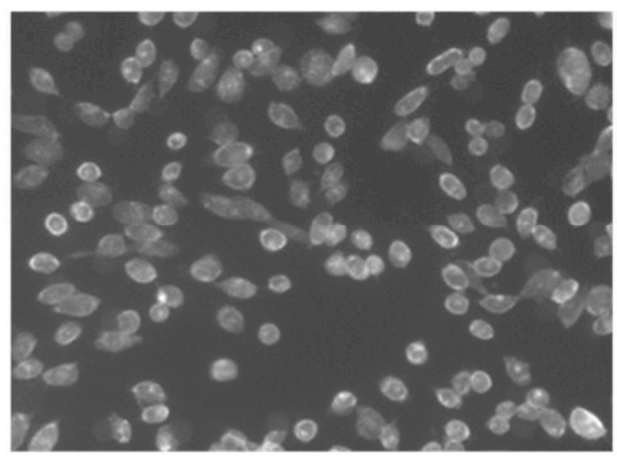

Pro5 ${ }^{\mathrm{mCD}}$ b
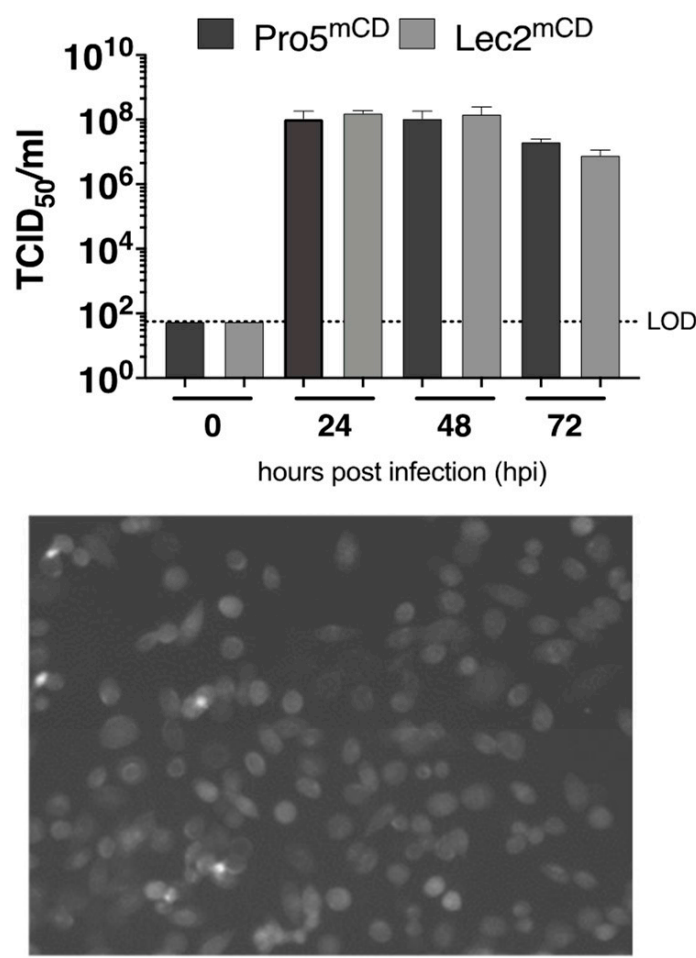

Lec2 $^{\mathrm{mCD}}$

Figure 5. Sialic acid deficient CHO cells expressing the MNV receptor mCD300LF support MNV-1 infection. Parental Pro5 and recombinant Lec2 cells deficient in CMP-sialic acid transport into the Golgi were transduced with the MNV entry receptor mCD300LF to make them susceptible to MNV infection. (a) The transduced cells were inoculated with MNV-1 (CW3) at MOI 5 on ice, the inoculum was removed, and cells were immediately lysed, and viral titers were determined by end-point titration. (b) The transduced cells were infected with MNV-1 (CW3) at MOI 0.05, the inoculum was removed, and cells were incubated between 0 and $72 \mathrm{~h}$. Viral titers were determined by end-point titration. Infections were performed in duplicate in the three independent experiments $(n=3)$. Error bars represent the standard error of the mean (SEM). (c) Sialic acid surface exposition was determined by immunohistochemistry using FITC-conjugated wheat-germ agglutinin.

\subsection{Glycan Binding to HuNoV P-Domains Has No Equivalent in MNV P-Dimers}

Binding of HBGAs to HuNoV P-domains is well documented by a number of crystallographic studies, by NMR experiments, by mass spectrometry, and by other biophysical techniques, providing a molecular basis for potential explanations of the importance of HBGAs for infection with HuNoVs. However, a convincing molecular model describing a mechanism of how exactly HBGAs promote infection $[7,8,33,55,56]$ in analogy to, e.g., prototypic SV40-ganglioside interactions [57-59] is still missing. In this context, it is very likely that additional factors including possibly even a proteinaceous receptor as recently identified for MNV $[15,16]$ contribute to HuNoV. Evaluation of studies addressing MNV/glycan or $\mathrm{HuNoV} /$ glycan interactions in combination with recent observations in our laboratory raises concerns about the validity of current data interpretation. One inconsistency emerges 
with respect to the order of magnitude of HBGA/HuNoV P-domain interactions, which had been described as ranging from low $\mu \mathrm{M}$ to low $\mathrm{mM}$ dissociation constants. However, recent CSP NMR experiments [35] suggest real affinities may be up to an order of magnitude weaker. The absence of any structural data for norovirus P-domains complexed with sialic acid or sialoglycans represents another mystery, given that a number of studies imply binding to P-domains of MNV as well as of HuNoV. To resolve these conflicts, we examined representative P-domain/glycan interactions employing CSP and STD NMR experiments. CSP NMR experiments represent a highly sensitive tool for probing binding of ligands to target proteins under near-physiological conditions [43] and deliver a wealth of information ranging from binding topologies to allosteric networks to dissociation constants. Chemical shifts of backbone $\mathrm{H}^{\mathrm{N}}$ resonances reflect even subtle changes in the protein's environment such as small changes in $\mathrm{pH}$ or buffer composition, giving rise to noticeable CSPs. Even very low-affinity binding can be sensed as reflected by the observation of quantifiable CSPs upon binding of B-Tri 3 to fully deamidated Saga P-dimers (cf. Figure 1d). Therefore, if addition of a ligand molecule to a target protein does not induce measurable CSPs it must be concluded that there is no interaction between that protein and the ligand.

In the case of GII.4 Saga P-dimers, we accomplished an almost complete backbone assignment, allowing identification of ligand binding topologies and affinities based on specific CSPs [35,36]. For the other GII.4 P-dimers used in this study no exhaustive assignment is available yet, but some backbone $\mathrm{H}^{\mathrm{N}}$ resonances could be identified by comparing to the almost sequence-identical Saga strain (Figure S1). For MNV P-domains the situation is more complicated since monomers and dimers are present in solution, and only addition of GCDCA triggers the formation of stable dimers (see the accompanying paper), likely different from the dimers in the absence of GCDCA. Since no CSPs were observed in any of the TROSY HSQC spectra assignments were unnecessary at this point.

\section{Discussion and Conclusions}

Our results indicate that some of the previous hypotheses regarding glycan recognition by noroviruses need to be revised, as will be briefly discussed in the following.

First, previously reported affinities of HBGAs binding to GII.4 P-dimers are up to an order of magnitude too large (Table 1). A follow up study in our laboratory systematically addressed the binding of HBGAs and other glycans to GII.4 P-dimers, significantly extending the current dataset [60]. In preceding NMR-based studies, we observed discontinuities in STD NMR titration curves leading to the hypothesis of cooperative binding and yielding apparent dissociation constants in the low $\mu \mathrm{M}$ range $[21,26,27]$. In light of our new systematic NMR binding studies, this hypothesis can no longer be maintained. Reevaluation of our old STD NMR titration data, ignoring the steps and assuming a simple one-site binding model, leads to very similar dissociation constants compared to the CSPderived data presented here. In another previous STD NMR-based study, sub millimolar dissociation constants had been reported for the binding of L-fucose and citrate to GII.10 P-dimers [28]. The reason simply is that in this case, titrations were stopped at ligand concentrations corresponding to the first "step" in the STD NMR titration curve, that can easily be mistaken as the saturation of binding. Although we have not yet resolved the precise origin of the STD NMR titration curve discontinuities, it appears that bulk effects perhaps involving ligand-ligand interactions are responsible. This is substantiated by the observation that the discontinuities strongly depend on $\mathrm{pH}$ and almost disappear under certain conditions, e.g., using BisTris buffer at slightly acidic $\mathrm{pH}$ [27]. In the case of MS-derived dissociation constants [29-31] there seems to be a fundamental problem due to specific structural features of P-domains. Recent systematic MS studies [61] suggest that the high content of $\beta$-sheet regions in P-dimers allows for intercalation of glycans in the gas phase, making elimination of unspecific binding very difficult and leading to false positive detection of binding.

Second, neither HuNoV GII.4 or GII.10 P-domains nor MNV P-domains recognize the analyzed sialylated glycans (cf. Tables 2 and 3). These observations are supported by 
previous findings showing that the sialic residue of sialyl Lewis ${ }^{\mathrm{x}}$ is not involved in binding to GII.4 VLPs [25] or to GII.9 P-domains [62]. Therefore, it must be concluded that previous MS-based data on binding of ganglioside derived glycans to GII.4 VA387 P-domains [22] are due to the formation of artificial associates of sialoglycans and P-domains in the gas phase after Coulomb explosion [61]. Our NMR experiments unambiguously show that sialic acid or sialic bearing glycans neither bind to VA387 P-dimers nor to other P-domains of GII.4 strains tested here (Table 3). This is in accordance with available biological data providing no hint that sialoglycans promote $\mathrm{HuNoV}$ infection. On the other hand, it has been shown that sialyl lacto- $N$-tetraose bearing neoglycoproteins inhibit binding of GII.3 (Chron1) and GII.4 (Dijon) VLPs to HBGA-containing human saliva [63], suggesting that intact capsids may exploit more complex mechanisms for glycan recognition than isolated P-dimers. It remains an open and interesting question how such mechanisms are put into effect.

For MNV, biological evidence implies the involvement of sialoglycans in MNV-1 infection $[19,20,64]$. At first glance, this cannot be reconciled with the observations presented here. Although it was shown in the past by competition experiments that the MNV-1 P-domain resembles the biologically active form [65], this may not apply to possible sialic acid binding sites. Available crystal structures of the MNV-1 P-domain describe an open (PDB: 3LQ6) and a closed conformation (PDB: 6C6Q, 6E47) with significant structural differences in the $\mathrm{A}^{\prime} \mathrm{B}^{\prime}$-loop and the $\mathrm{C}^{\prime} \mathrm{D}^{\prime}$-loop. Ligands such as bile acids and bivalent cations contribute to these structural differences. Here, binding to sialoglycans was neither affected by the presence of bile acid nor by bivalent cations; however, the involvement of as yet unknown co-factors for sialoglycan binding cannot be ruled out. Our cell culture experiments performed here with a novel cell line artificially expressing the entry receptor mCD300LF and devoid of surface sialoglycans further suggest that sialoglycans do not play a major role in MNV-1 binding and infection. This is supported by strain-specific differences in the sensitivity to neuraminidase treatment as shown previously.

Third, MNV P-domains neither bind to HBGAs nor to other glycans studied here (Table 2). Taken together, our data suggest that glycan recognition through P-domains is a distinct feature of $\mathrm{HuNoV}$ and absent for MNV.

To conclude, our results essentially redefine the glycan recognition code for norovirus P-dimers and prompt for new experiments on the biological side, eventually decrypting hitherto unknown mechanism of how glycans modulate norovirus infection.

Supplementary Materials: The following are available online at https:/ / www.mdpi.com/1999-491 5/13/3/416/s1, Figure S1: ${ }^{1} \mathrm{H},{ }^{15} \mathrm{~N}$ TROSY HSQC spectra of $\left[U-{ }^{2} \mathrm{H}_{,}{ }^{15} \mathrm{~N}\right]$-labeled P-dimers of different GII.4 strains and sequence alignment of the respective GII.4 P-domains; Figure S2: Deamidation of GII.4 strains MI001 and Saga; Figure S3: IEX experiments with GII.4 Saga N373D show stability at $25{ }^{\circ} \mathrm{C}$ for weeks; Figure S4: Re-evaluation of previously reported binding isotherms STD; Figure S5: Binding of $\mathrm{Mn}^{2+}$ impurities in chemo-enzymatically synthesized B-trisaccharide to $\left[U-{ }^{2} \mathrm{H},{ }^{15} \mathrm{~N}\right]-$ labeled MNV CW1 P-domain; Figure S6: Additional CSP titration curves for A-Tri 2 binding to $\left[U-{ }^{2} \mathrm{H},{ }^{15} \mathrm{~N}\right]$-labeled Saga GII.4 P-dimers; Figure S7: ${ }^{1} \mathrm{H},{ }^{15} \mathrm{~N}$ TROSY HSQC spectra showing no binding of sialylated ganglioside glycans to human NoV GII.4 P-domains as summarized in Table 3; Figure S8: ${ }^{1} \mathrm{H},{ }^{15} \mathrm{~N}$ TROSY HSQC and STD NMR spectra showing no binding of sialylated ganglioside glycans to murine NoV P-domains CW1 and MNV07 as summarized in Table 2; Table S1: Experimental conditions for data in Table 2; Table S2: Source of glycans; Table S3: Assignment of blood group B trisaccharide; Table S4: NMR experiments and experimental conditions used for the assignment of blood group B trisaccharide 3; Table S5: Reevaluation of dissociation constants $\mathrm{K}_{\mathrm{D}}$ based on previously reported titrations.

Author Contributions: Conceptualization, T.P. and S.T.; methodology, R.C., T.M., H.P., T.P., S.T., and A.M.; software, R.C., T.M., A.M.; investigation, R.C., T.M., P.O., G.W., C.F., H.P., M.L., A.M.; resources, T.P. and S.T.; data curation, R.C., T.M., A.M., S.T. and T.P.; writing-T.P., R.C., T.M., A.M., and S.T.; writing-review and editing, R.C., T.M., P.O., G.W., C.F., H.P., M.L., S.T., T.P., and A.M.; supervision, T.P., S.T., and A.M.; project administration, T.P. and S.T.; funding acquisition, T.P. and S.T. All authors have read and agreed to the published version of the manuscript. 
Funding: This research was funded by the Deutsche Forschungsgemeinschaft (DFG) via grants Pe494/122 (T.P.) and TA1093-2 (S.T.) within the research unit FOR2327 (ViroCarb). T.P. thanks the State of Schleswig-Holstein for supplying the NMR infrastructure (European Funds for Regional Development, LPW-E/1.1.2/857). P.O. and C.F. thank the Studienstiftung des deutschen Volkes for fellowships.

Institutional Review Board Statement: Not applicable.

Informed Consent Statement: Not applicable.

Data Availability Statement: All data are included in this manuscript and in the supporting information.

Acknowledgments: We would like to thank Thorsten Biet for support with the NMR experiments, and Javier Pérez Castells (University CEU San Pablo, Madrid, Spain) for providing us with blood group $\mathrm{H}$ disaccharide. We acknowledge the many discussions with Charlotte Uetrecht and Jasmin Dülfer (Heinrich Pette Institute, Hamburg) on the issues with native MS when studying ligand binding to P-dimers, and we very much appreciate having had access to the corresponding MS data prior to publication. The lentivirus system was a generous gift from Didier Trono (University of Geneva, Switzerland), who provided the packaging vector (pCMV $\Delta$ R8.91) and the vector expressing VSV-G (pMD.G) and Thomas Pietschmann (Twincore, Hannover, Germany), who provided the pWPI msc GUN vector. We are also very grateful to Niklas Arnberg (Umeå University, Umeå, Sweden) for providing the $\mathrm{CHO}$ cell lines Pro5 and Lec2.

Conflicts of Interest: The authors declare no conflict of interest.

\section{References}

1. Chhabra, P.; De Graaf, M.; Parra, G.I.; Chan, M.C.-W.; Green, K.; Martella, V.; Wang, Q.; White, P.A.; Katayama, K.; Vennema, H.; et al. Updated classification of norovirus genogroups and genotypes. J. Gen. Virol. 2019, 100, 1393-1406. [CrossRef]

2. $\quad$ van Beek, J.; de Graaf, M.; Al-Hello, H.; Allen, D.J.; Ambert-Balay, K.; Botteldoorn, N.; Koopmans, M.P. Molecular surveillance of norovirus, 2005-16: An epidemiological analysis of data collected from the NoroNet network. Lancet Infect. Dis. 2018, 18, 545-553. [CrossRef]

3. de Graaf, M.; van Beek, J.; Koopmans, M.P. Human norovirus transmission and evolution in a changing world. Nat. Rev. Microbiol. 2016, 14, 421-433. [CrossRef]

4. Cao, S.; Lou, Z.; Tan, M.; Chen, Y.; Liu, Y.; Zhang, Z.; Zhang, X.C.; Jiang, X.; Li, X.; Rao, Z. Structural basis for the recognition of blood group trisaccharides by norovirus. J. Virol. 2007, 81, 5949-5957. [CrossRef]

5. Huang, P.; Farkas, T.; Marionneau, S.; Zhong, W.; Ruvoën-Clouet, N.; Morrow, A.L.; Altaye, M.; Pickering, L.K.; Newburg, D.S.; LePendu, J.; et al. Noroviruses bind to human ABO, Lewis, and secretor histo-blood group antigens: Identification of 4 distinct strain-specific patterns. J. Infect. Dis. 2003, 188, 19-31. [CrossRef]

6. Marionneau, S.; Ruvoën, N.; Le Moullac-Vaidye, B.; Clement, M.; Cailleau-Thomas, A.; Ruiz-Palacois, G.; Huang, P.; Jiang, X.; Le Pendu, J. Norwalk virus binds to histo-blood group antigens present on gastroduodenal epithelial cells of secretor individuals. Gastroenterology 2002, 122, 1967-1977. [CrossRef] [PubMed]

7. Bartnicki, E.; Cunha, J.B.; Kolawole, A.O.; Wobus, C.E. Recent advances in understanding noroviruses. F1000Research 2017, 6, 79. [CrossRef] [PubMed]

8. Karst, S.M.; Wobus, C.E. A working model of how noroviruses infect the intestine. PLOS Pathog. 2015, 11, e1004626. [CrossRef]

9. Singh, B.K.; Leuthold, M.M.; Hansman, G.S. Structural Constraints on Human Norovirus Binding to Histo-Blood Group Antigens. mSphere 2016, 1, e00049-16. [CrossRef] [PubMed]

10. Carmona-Vicente, N.; Vila-Vicent, S.; Allen, D.; Gozalbo-Rovira, R.; Iturriza-Gómara, M.; Buesa, J.; Rodríguez-Díaz, J. Characterization of a Novel Conformational GII.4 Norovirus Epitope: Implications for Norovirus-Host Interactions. J. Virol. 2016, 90, 7703-7714. [CrossRef]

11. Guix, S.; Asanaka, M.; Katayama, K.; Crawford, S.E.; Neill, F.H.; Atmar, R.L.; Estes, M.K. Norwalk virus RNA is infectious in mammalian cells. J. Virol. 2007, 81, 12238-12248. [CrossRef]

12. Haga, K.; Ettayebi, K.; Tenge, V.R.; Karandikar, U.C.; Lewis, M.A.; Lin, S.-C.; Neill, F.H.; Ayyar, B.V.; Zeng, X.-L.; Larson, G.; et al. Genetic Manipulation of Human Intestinal Enteroids Demonstrates the Necessity of a Functional Fucosyltransferase 2 Gene for Secretor-Dependent Human Norovirus Infection. mBio 2020, 11. [CrossRef]

13. Nelson, C.A.; Wilen, C.B.; Dai, Y.-N.; Orchard, R.C.; Kim, A.S.; Stegeman, R.A.; Hsieh, L.L.; Smith, T.J.; Virgin, H.W.; Fremont, D.H. Structural basis for murine norovirus engagement of bile acids and the CD300lf receptor. Proc. Natl. Acad. Sci. USA 2018. [CrossRef] [PubMed]

14. Kilic, T.; Koromyslova, A.; Malak, V.; Hansman, G.S. Atomic structure of the murine norovirus protruding domain and sCD3001f receptor complex. J. Virol. 2018, 92. [CrossRef]

15. Haga, K.; Fujimoto, A.; Takai-Todaka, R.; Miki, M.; Doan, Y.H.; Murakami, K.; Yokoyama, M.; Murata, K.; Nakanishi, A.; Katayama, K. Functional receptor molecules CD300lf and CD300ld within the CD300 family enable murine noroviruses to infect cells. Proc. Natl. Acad. Sci. USA 2016. [CrossRef] 
16. Orchard, R.C.; Wilen, C.B.; Doench, J.G.; Baldridge, M.T.; McCune, B.T.; Lee, Y.-C.J.; Lee, S.; Pruett-Miller, S.M.; Nelson, C.A.; Fremont, D.H.; et al. Discovery of a proteinaceous cellular receptor for a norovirus. Science 2016, 353, 933-936. [CrossRef]

17. Stuart, A.D.; Brown, T.D.K. Alpha2,6-linked sialic acid acts as a receptor for Feline calicivirus. J. Gen. Virol. 2007, 88, 177-186. [CrossRef] [PubMed]

18. Tan, M.; Wei, C.; Huang, P.; Fan, Q.; Quigley, C.; Xia, M.; Fang, H.; Zhang, X.; Zhong, W.; Klassen, J.S.; et al. Tulane virus recognizes sialic acids as cellular receptors. Sci. Rep. 2015, 5, 11784. [CrossRef] [PubMed]

19. Taube, S.; Perry, J.W.; Yetming, K.; Patel, S.P.; Auble, H.; Shu, L.; Nawar, H.F.; Lee, C.H.; Connell, T.D.; Shayman, J.A.; et al. Ganglioside-linked terminal sialic acid moieties on murine macrophages function as attachment receptors for murine noroviruses. J. Virol. 2009, 83, 4092-4101. [CrossRef]

20. Taube, S.; Perry, J.W.; McGreevy, E.; Yetming, K.; Perkins, C.; Henderson, K.; Wobus, C.E. Murine noroviruses bind glycolipid and glycoprotein attachment receptors in a strain-dependent manner. J. Virol. 2012, 86, 5584-5593. [CrossRef] [PubMed]

21. Wegener, H.; Mallagaray, Á.; Schöne, T.; Peters, T.; Lockhauserbäumer, J.; Yan, H.; Uetrecht, C.; Hansman, G.S.; Taube, S. Human norovirus GII.4(MI001) P dimer binds fucosylated and sialylated carbohydrates. Glycobiology 2017, 27, 1027-1037. [CrossRef] [PubMed]

22. Han, L.; Tan, M.; Xia, M.; Kitova, E.N.; Jiang, X.; Klassen, J.S. Gangliosides are ligands for human noroviruses. J. Am. Chem. Soc. 2014, 136, 12631-12637. [CrossRef] [PubMed]

23. Taube, S.; Mallagaray, A.; Peters, T. Norovirus, glycans and attachment. Curr. Opin. Virol. 2018, 31, 33-42. [CrossRef]

24. Shanker, S.; Hu, L.; Ramani, S.; Atmar, R.L.; Estes, M.K.; Prasad, B.V.V. Structural features of glycan recognition among viral pathogens. Curr. Opin. Struct. Biol. 2017, 44, 211-218. [CrossRef]

25. Fiege, B.; Rademacher, C.; Cartmell, J.; Kitov, P.I.; Parra, F.; Peters, T. Molecular Details of the Recognition of Blood Group Antigens by a Human Norovirus as Determined by STD NMR Spectroscopy. Angew. Chem. Int. Ed. 2012, 51, 928-932. [CrossRef] [PubMed]

26. Mallagaray, A.; Rademacher, C.; Parra, F.; Hansman, G.; Peters, T. STD NMR Titrations Reveal Complex Multistep-Binding of L-Fucose to Norovirus Particles. Glycobiology 2017, 27, 80-86. [CrossRef] [PubMed]

27. Mallagaray, A.; Lockhauserbäumer, J.; Hansman, G.; Uetrecht, C.; Peters, T. Attachment of Norovirus to Histo Blood Group Antigens: A Cooperative Multistep Process. Angew. Chem. Int. Ed. 2015, 54, 12014-12019. [CrossRef] [PubMed]

28. Hansman, G.S.; Shahzad-Ul-Hussan, S.; McLellan, J.S.; Chuang, G.-Y.; Georgiev, I.; Shimoike, T.; Katayama, K.; Bewley, C.A.; Kwong, P.D. Structural basis for norovirus inhibition and fucose mimicry by citrate. J. Virol. 2012, 86, 284-292. [CrossRef] [PubMed]

29. Han, L.; Zheng, R.; Richards, M.R.; Tan, M.; Kitova, E.N.; Jiang, X.; Klassen, J.S. Quantifying the Binding Stoichiometry and Affinity of Histo-Blood Group Antigen Oligosaccharides for Human Noroviruses. Glycobiology 2018, 28, 488-498. [CrossRef]

30. Han, L.; Kitova, E.N.; Tan, M.; Jiang, X.; Pluvinage, B.; Boraston, A.B.; Klassen, J.S. Affinities of human histo-blood group antigens for norovirus capsid protein complexes. Glycobiology 2015, 25, 170-180. [CrossRef] [PubMed]

31. Han, L.; Kitov, P.I.; Kitova, E.N.; Tan, M.; Wang, L.; Xia, M.; Jiang, X.; Klassen, J.S. Affinities of recombinant norovirus P dimers for human blood group antigens. Glycobiology 2013, 23, 276-285. [CrossRef] [PubMed]

32. Nasir, W.; Bally, M.; Zhdanov, V.P.; Larson, G.; Höök, F. Interaction of Virus-Like Particles with Vesicles Containing Glycolipids: Kinetics of Detachment. J. Phys. Chem. B 2015, 119, 11466-11472. [CrossRef]

33. Parveen, N.; Rydell, G.E.; Larson, G.; Hytönen, V.P.; Zhdanov, V.P.; Höök, F.; Block, S. Competition for Membrane Receptors: Norovirus Detachment via Lectin Attachment. J. Am. Chem. Soc. 2019, 141, 16303-16311. [CrossRef] [PubMed]

34. Nasir, W.; Frank, M.; Kunze, A.; Bally, M.; Parra, F.; Nyholm, P.-G.; Höök, F.; Larson, G. Histo-Blood Group Antigen Presentation Is Critical for Binding of Norovirus VLP to Glycosphingolipids in Model Membranes. ACS Chem. Biol. 2017, 12, 1288-1296. [CrossRef] [PubMed]

35. Mallagaray, A.; Creutznacher, R.; Dülfer, J.; Mayer, P.H.O.; Grimm, L.L.; Orduña, J.M.; Trabjerg, E.; Stehle, T.; Rand, K.D.; Blaum, B.S.; et al. A post-translational modification of human Norovirus capsid protein attenuates glycan binding. Nat. Commun. 2019, 10, 1320. [CrossRef]

36. Creutznacher, R.; Schulze, E.; Wallmann, G.; Peters, T.; Stein, M.; Mallagaray, A. Chemical-Shift Perturbations Reflect Bile Acid Binding to Norovirus Coat Protein: Recognition Comes in Different Flavors. ChemBioChem 2020, 21, 1007-1021. [CrossRef] [PubMed]

37. Hansman, G.S.; Doan, L.T.P.; Kguyen, T.A.; Okitsu, S.; Katayama, K.; Ogawa, S.; Natori, K.; Takeda, N.; Kato, Y.; Nishio, O.; et al. Detection of norovirus and sapovirus infection among children with gastroenteritis in Ho Chi Minh City, Vietnam. Arch. Virol. 2004, 149, 1673-1688. [CrossRef] [PubMed]

38. Seto, N.O.; Compston, C.A.; Szpacenko, A.; Palcic, M.M. Enzymatic synthesis of blood group A and B trisaccharide analogues. Carbohydr. Res. 2000, 324, 161-169. [CrossRef]

39. Angulo, J.; Langpap, B.; Blume, A.; Biet, T.; Meyer, B.; Krishna, N.R.; Peters, H.; Palcic, M.M.; Peters, T. Blood Group B Galactosyltransferase: Insights into Substrate Binding from NMR Experiments. J. Am. Chem. Soc. 2006, 128, 13529-13538. [CrossRef]

40. Sindhuwinata, N.; Munoz, E.; Munoz, F.J.; Palcic, M.M.; Peters, H.; Peters, T. Binding of an acceptor substrate analog enhances the enzymatic activity of human blood group B galactosyltransferase. Glycobiology 2010, 20, 718-723. [CrossRef] 
41. Baryshnikova, O.K.; Williams, T.C.; Sykes, B.D. Internal pH indicators for biomolecular NMR. J. Biomol. NMR 2008, 41, 5-7. [CrossRef]

42. Vranken, W.F.; Boucher, W.; Stevens, T.J.; Fogh, R.H.; Pajon, A.; Llinas, M.; Ulrich, E.L.; Markley, J.L.; Ionides, J.; Laue, E.D. The CCPN data model for NMR spectroscopy: Development of a software pipeline. Proteins Struct. Funct. Bioinform. 2005, 59, 687-696. [CrossRef]

43. Williamson, M.P. Using chemical shift perturbation to characterise ligand binding. Prog. Nucl. Magn. Reson. Spectrosc. 2013, 73, 1-16. [CrossRef] [PubMed]

44. Mayer, M.; Meyer, B. Characterization of Ligand Binding by Saturation Transfer Difference NMR Spectroscopy. Angew. Chem. Int. Ed. 1999, 38, 1784-1787. [CrossRef]

45. Hwang, S.; Alhatlani, B.; Arias, A.; Caddy, S.L.; Christodoulou, C.; Cunha, J.B.; Emmott, E.; Gonzalez-Hernandez, M.; Kolawole, A.; Lu, J.; et al. Murine Norovirus: Propagation, quantification, and genetic manipulation. Curr. Protoc. Microbiol. 2014, 33, 15K.2.1-15K.2.61. [CrossRef] [PubMed]

46. Zufferey, R.; Nagy, D.; Mandel, R.J.; Naldini, L.; Trono, D. Multiply attenuated lentiviral vector achieves efficient gene delivery in vivo. Nat. Biotechnol. 1997, 15, 871-875. [CrossRef]

47. Naldini, L.; Blomer, U.; Gage, F.H.; Trono, D.; Verma, I.M. Efficient transfer, integration, and sustained long-term expression of the transgene in adult rat brains injected with a lentiviral vector. Proc. Natl. Acad. Sci. USA 1996, 93, 11382-11388. [CrossRef]

48. Kaludov, N.; Brown, K.E.; Walters, R.W.; Zabner, J.; Chiorini, J.A. Adeno-associated virus serotype 4 (AAV4) and AAV5 both require sialic acid binding for hemagglutination and efficient transduction but differ in sialic acid linkage specificity. J. Virol. 2001, 75, 6884-6893. [CrossRef] [PubMed]

49. Galili, U.; Mandrell, R.E.; Hamadeh, R.M.; Shohet, S.B.; Griffiss, J.M. Interaction between human natural anti-alpha-galactosyl immunoglobulin $\mathrm{G}$ and bacteria of the human flora. Infect. Immun. 1988, 56, 1730-1737. [CrossRef]

50. Zakhour, M.; Ruvoen-Clouet, N.; Charpilienne, A.; Langpap, B.; Poncet, D.; Peters, T.; Bovin, N.; Le Pendu, J. The aGal Epitope of the Histo-Blood Group Antigen Family Is a Ligand for Bovine Norovirus Newbury2 Expected to Prevent Cross-Species Transmission. PLoS Pathog. 2009, 5, e1000504. [CrossRef]

51. Hakomori, S.I. Tumor-Associated Carbohydrate Antigens. Annu. Rev. Immunol. 1984, 2, 103-126. [CrossRef] [PubMed]

52. Müller-Hermes, C.; Creutznacher, R.; Mallagaray, A. Complete assignment of Ala, Ile, Leu(ProS), Met and Val(ProS) methyl groups of the protruding domain from human norovirus GII.4 Saga. Biomol. NMR Assign. 2020, 14, 123-130. [CrossRef] [PubMed]

53. Kilic, T.; Koromyslova, A.; Hansman, G.S. Structural Basis for Human Norovirus Capsid Binding to Bile Acids. J. Virol. 2019, 93, e01581-18. [CrossRef]

54. Stott, K.; Stonehouse, J.; Keeler, J.; Hwang, T.-L.; Shaka, A.J. Excitation Sculpting in High-Resolution Nuclear Magnetic Resonance Spectroscopy: Application to Selective NOE Experiments. J. Am. Chem. Soc. 1995, 117, 4199-4200. [CrossRef]

55. Rydell, G.; Svensson, L.; Larson, G.; Johannes, L.; Römer, W. Human GII.4 norovirus VLP induces membrane invaginations on giant unilamellar vesicles containing secretor gene dependent alpha1,2-fucosylated glycosphingolipids. Biochim. Biophys. Acta 2013, 1828, 1840-1845. [CrossRef]

56. Rydell, G.E.; Dahlin, A.B.; Höök, F.; Larson, G. QCM-D studies of human norovirus VLPs binding to glycosphingolipids in supported lipid bilayers reveal strain-specific characteristics. Glycobiology 2009, 19, 1176-1184. [CrossRef] [PubMed]

57. Ewers, H.; Roemer, W.; Smith, A.E.; Bacia, K.; Dmitrieff, S.; Chai, W.; Mancini, R.; Kartenbeck, J.; Chambon, V.; Berland, L.; et al. GM1 structure determines SV40-induced membrane invagination and infection. Nat. Cell Biol. 2010, 12, 11-18. [CrossRef] [PubMed]

58. Neu, U.; Woellner, K.; Gauglitz, G.; Stehle, T. Structural basis of GM1 ganglioside recognition by simian virus. Proc. Natl. Acad. Sci. USA 2008, 105, 5219-5224. [CrossRef]

59. Tsai, B.; Gilbert, J.M.; Stehle, T.; Lencer, W.; Benjamin, T.L.; Rapoport, T.A. Gangliosides are receptors for murine polyoma virus and SV40. EMBO J. 2003, 22, 4346-4355. [CrossRef]

60. Alvaro, M.; University of Lubeck, Lubeck, Germany. Personal communication, 2021.

61. Charlotte, U.; Heinrich Pette Institute, Hamburg, Germany. Personal communication, 2020.

62. Chen, Y.; Tan, M.; Xia, M.; Hao, N.; Zhang, X.C.; Huang, P.; Jiang, X.; Li, X.; Rao, Z. Crystallography of a Lewis-binding norovirus, elucidation of strain-specificity to the polymorphic human histo-blood group antigens. PLOS Pathog. 2011, 7, e1002152. [CrossRef]

63. Rydell, G.E.; Nilsson, J.; Rodriguez-Diaz, J.; Ruvoën-Clouet, N.; Svensson, L.; Le Pendu, J.; Larson, G. Human noroviruses recognize sialyl Lewis x neoglycoprotein. Glycobiology 2009, 19, 309-320. [CrossRef] [PubMed]

64. Taube, S.; Jiang, M.; Wobus, C.E. Glycosphingolipids as Receptors for non-enveloped viruses. Viruses 2010, 2, 1011-1049. [CrossRef] [PubMed]

65. Taube, S.; Rubin, J.R.; Katpally, U.; Smith, T.J.; Kendall, A.; Stuckey, J.A.; Wobus, C.E. High-resolution X-ray structure and functional analysis of the murine norovirus 1 capsid protein protruding domain. J. Virol. 2010, 84, 5695-5705. [CrossRef] [PubMed] 